Facultad de Ciencias Empresariales y Económicas

Carrera de Negocios Internacionales

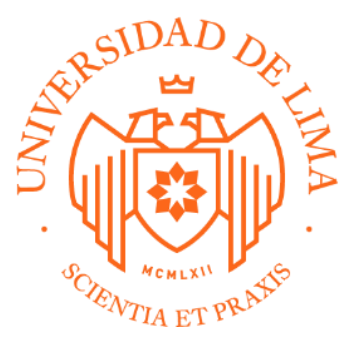

\title{
CASO DE ESTUDIO: IOI'S GLOBAL CHALLENGE: MOVING UP THE PALM OIL VALUE CHAIN
}

Trabajo de suficiencia profesional para optar el Título Profesional de Licenciado en Negocios Internacionales

Jose Alonso Buchhammer Arroyo

Código 20140189

\author{
Lima - Perú
}

Octubre del 2019 


\section{CASE OF STUDY: IOI'S GLOBAL CHALLENGE: MOVING UP THE PALM OIL VALUE CHAIN}




\section{TABLA DE CONTENIDO}

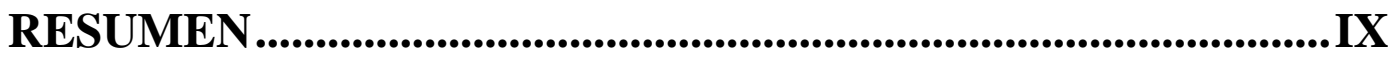

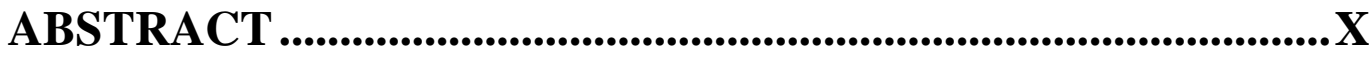

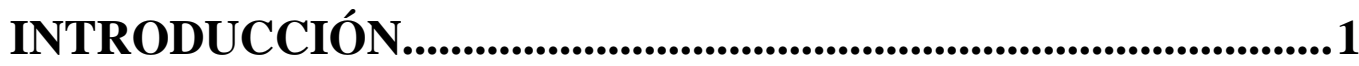

CAPÍTULO I: OBJETIVOS......................................................2

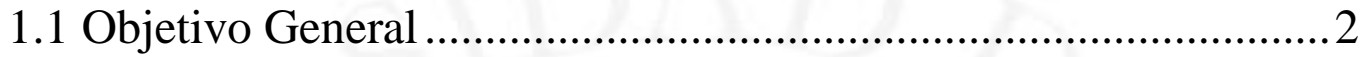

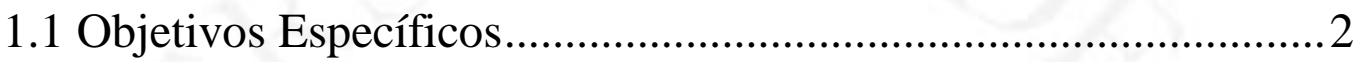

CAPÍTULO II: PREGUNTAS DE INVESTIGACIÓN..................3

2.1 Área Inteligencia de Mercados Internacionales.............................. 3

2.2 Área Mercadotecnia Internacional ............................................ 4

2.3 Área Strategic Global Management...............................................

2.4 Área Logística del Comercio Internacional .................................6

2.5 Área Financiamiento Internacional ............................................ 7

CAPÍTULO III: METODOLOGÍA DE RECOLECCIÓN DE LA

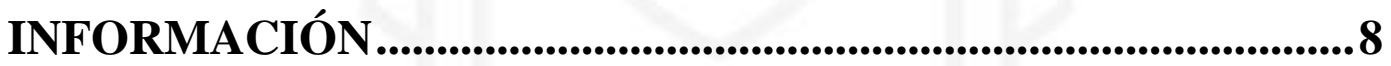

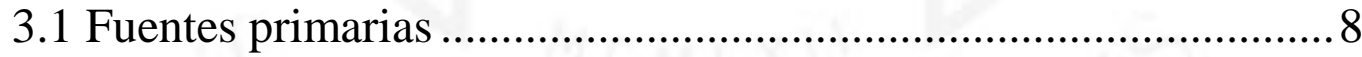

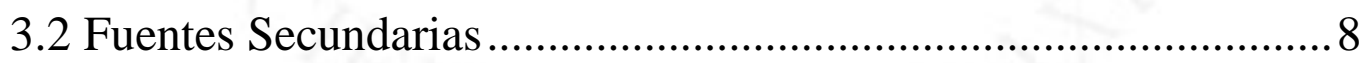

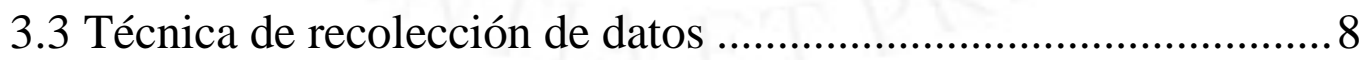

CAPÍTULO IV: METODOLOGÍA DE ANÁLISIS DE LA

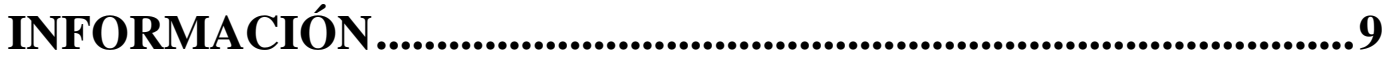

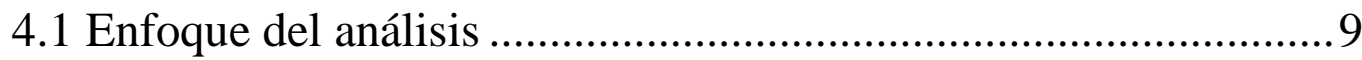

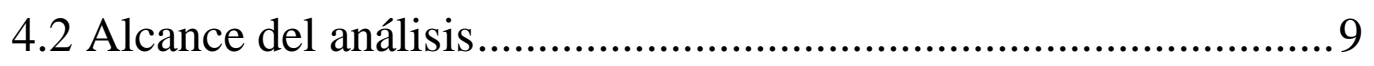

CAPÍTULO V: DESCRIPCIÓN DEL CASO.................................10 


\section{CAPÍTULO VI: ANÁLISIS Y DISCUSIÓN DE RESULTADOS}

\section{1}

6.1 Área Inteligencia de Mercados Internacionales.............................. 11

6.2 Área Mercadotecnia Internacional .............................................. 14

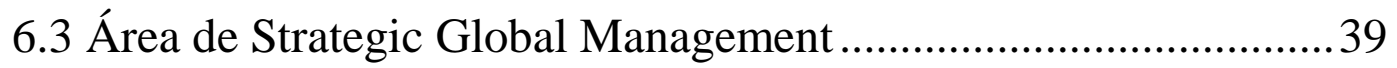

6.4 Área Logística del Comercio Internacional ...................................47

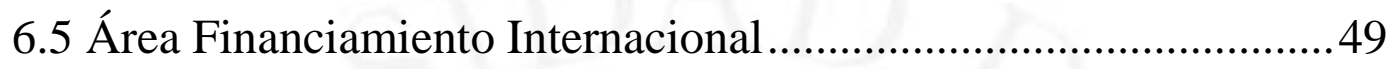

CONCLUSIONES...................................................................................53

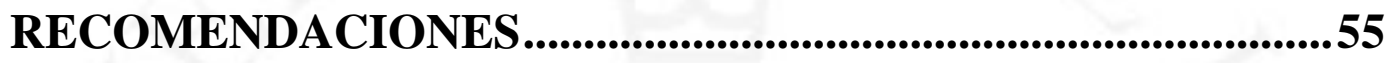

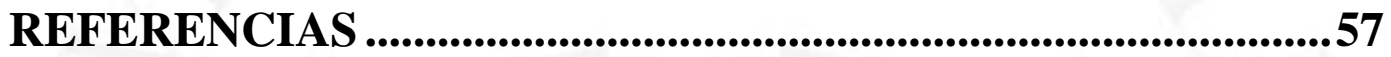

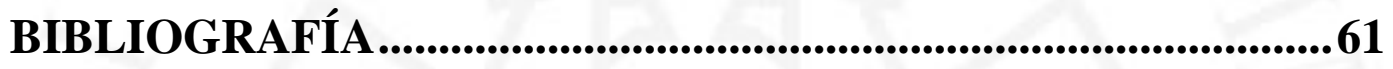

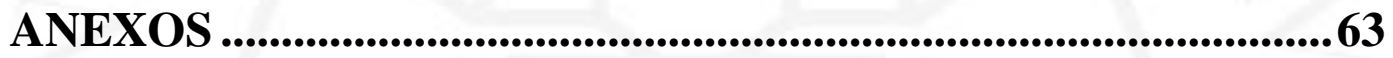




\section{ÍNDICE DE FIGURAS}

Figura 6.1 Enfoque de Nido de Shapiro y Bonoma ................................................... 19

Figura 6.2 Matric Boston Consulting Group de IOI ...................................................28

Figura 6.3 Matriz Interna-Externa de McKinsey y Company ….................................. 30

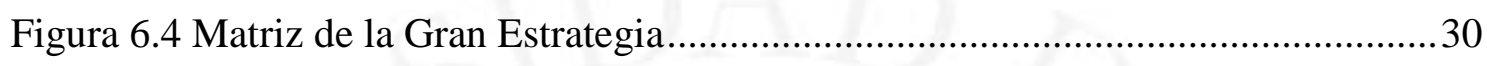

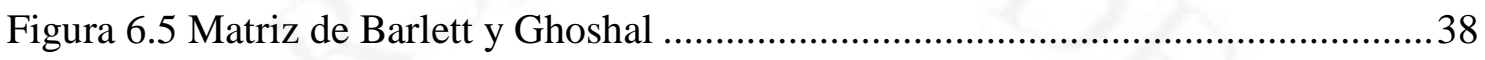




\section{ÍNDICE DE TABLAS}

Tabla 6.1 Ranking de Factores de los 5 principales países importadores de aceite de palma

Tabla 6.2 Tamaño de mercado de Vietnam en miles de toneladas. .12

Tabla 6.3 Ranking de Factores de principales países emergentes .13

Tabla 6.4 Matriz de diferenciación de segmentos y productos de IOI .16

Tabla 6.5 Matriz de Perfil de Clientes de IOI. 17

Tabla 6.6 Matriz de Factores Externos .21

Tabla 6.7 Matriz de Factores Internos .22

Tabla 6.8 Matriz de las 5 fuerzas de Michael Porter .23

Tabla 6.9 Matriz de Estrategia de Comunicaciones .28

Tabla 6.10 Matrices de Posición Competitiva y Atractividad de Mercado .32

Tabla 6.11 Matriz FODA de IOI .34

Tabla 6.12 Matriz de Decisión Estratégica. .37

Tabla 6.13 Matriz FODA de empresas familiares 41

Tabla 6.14 Valorización IOI por método VPA .50

Tabla 6.15 Valorización IOI por método WACC. .50

Tabla 6.16 Supuestos para la proyección financiera de IOI .51 


\section{ÍNDICE DE ANEXOS}

Anexo 1 Ingresos por segmento de principales competidores en la industria de Aceite de

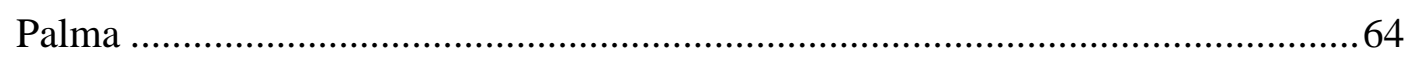

Anexo 2 Crecimiento anual ponderado de segmentos de IOI ....................................65

Anexo 3 Participación relativa de IOI en sus segmentos..........................................66

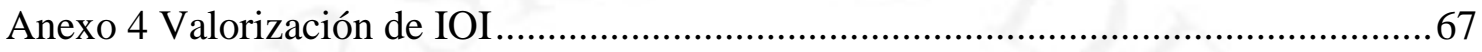

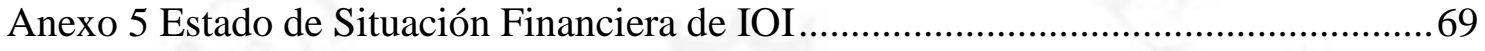

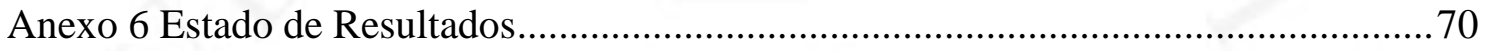




\section{RESUMEN}

El objetivo del presente caso es evaluar a IOI Corporation Berhad, determinando cuantitativamente el nivel de éxito y de competitividad que esta ha tenido durante el periodo entre los años 2012 y 2017. Para esto, se analizó el desempeño del grupo en las áreas de inteligencia de mercados, mercadotecnia internacional, strategic global management, logística de comercio y finanzas internacionales en la industria global de aceite de palma.

Para este análisis, se consideraron las características diferenciales de este caso debido al contexto en el que se encuentra la empresa. En primer lugar, IOI es una empresa familiar y debido a esto ha enfrentado estigmatismos que suponen una empresa de esta naturaleza, pero que a pesar de estos se ha mantenido siendo profesional e incluso con un enfoque en diferenciación no usual en empresas de este tipo, sin embargo los riesgos de caer en un nepotismo que brinde pocas eficiencias o el conservadurismo de las cabezas de la empresa siguen latentes. En segundo lugar, esta exitosa empresa ha enfrentado dos crisis en el último quinquenio, viendo afectada su sostenibilidad financiera y dañando su imagen, obligando a IOI a examinar sus estrategias financieras y de comunicación solamente para actuar de manera reactiva, cuando la empresa ya estuvo sumergida en ambas crisis. Por último, y como ya se mencionó, IOI ha invertido bastos recursos en su estrategia de diferenciación, adquiriendo Loders Croklaan para la investigación y desarrollo de nuevos productos y empleo de estos dentro de la industria de aceite de palma, viendo esta estrategia como su estandarte y principal valor agregado frente a una competencia global ciertamente fragmentada.

Es por estos motivos que el caso de esta empresa de origen malayo tiene factores diferenciales importantes que se medirán durante este caso para recomendar qué estrategias se deben seguir para continuar con la internacionalización de IOI.

Palabras clave: aceite de palma, empresa familiar, competitividad, sostenibilidad, internacionalización 


\begin{abstract}
The objective of this case is to evaluate IOI Corporation Berhad, determing quantitatively the level of success and competitiveness that it has had during the period between 2012 and 2017. To achieve this, the group's performance was analyzed in the areas of market intelligence, international marketing, Strategy Global Management, international commerce logistics and international finance in the global palm oil industry.

For this analysis, the differential characteristics of this case were considered due to the context in which the company is located. In the first place, IOI is a family business and because of this it has faced stigmatisms that suppose a company of this nature, but despite this it has remained professional and focused on differentiation strategies, unusual along this type of companies. However, the risks of falling into a nepotism that provides few efficiencies or the conservatism of company bosses remain latent. Secondly, this successful company has faced two crises in the last five years, affecting its financial sustainability and damaging its image, forcing IOI to examine its financial and communication strategies only to act reactively, when the company was already submerged in these events. Finally, and as already mentioned, IOI has invested vast resources in its differentiation strategy, acquiring Loders Croklaan for research, development of new products and their use within the palm oil industry, seeing this strategy as its most important added value against a global market which is certainly fragmented.

It is for these reasons that the case of this company of Malay has important differential factors that will be measured in order to recommend what strategies should be followed to continue the internationalization of IOI.
\end{abstract}

Key words: palm oil, family business, competitiveness, sustainability, internationalization 


\section{INTRODUCCIÓN}

La industria del aceite de palma ciertamente ha sido una realidad de nuestro mundo desde hace ya 5 mil años, siendo el primer registro la colocación de este aceite en sarcófagos egipcios. Sin embargo, el aceite de palma no tuvo fines industriales hasta el siglo XVIII en donde se comenzó a usar para hacer velas y como lubricante para maquinaria teniendo bastas plantaciones en África. Hoy en día, las plantaciones se ubican en el sudeste asiático, donde el producto de sus cosechas alimenta varias industrias modernas, como la de alimentos, farmacéutica, tecnológica e incluso la de energía, a través de la producción de biodiesel a base de palma. Es esta versatilidad y demanda ha hecho crecer a varias empresas globales, una de estas, IOI Corporation Berhad. El presente estudio analizará 5 áreas principalmente de esta compañía: Inteligencia de Mercados Internacionales, Mercadotecnia Internacional, Administración Estratégica Global, Logística del Comercio Internacional y Finanzas Internacionales, para evaluar su situación actual y determinar el éxito o fracaso de su trayectoria, y dar recomendaciones en base a los resultados.

Fundada en Malasia en 1969 y caracterizada por ser una empresa austera, impulsada por alcanzar sus objetivos con excelencia y un enfoque en diferenciación e innovación poco usual en la industria, se coloca como uno de los líderes de un mercado fragmentado por la alta competencia. Centralizando sus plantaciones en Malasia e Indonesia, ha expandido sus operaciones downstream a través de Europa, Norteamérica y Asia, ahora debe evaluar cuál debe ser su próximo paso hacia un crecimiento estratégico, teniendo en cuenta que recientemente ha superado una crisis de sostenibilidad que ha perjudicado a la empresa.

El contexto incluye una industria con alta volatilidad en la demanda e inestabilidad en los precios del aceite de palma, fenómenos naturales ajenos al control de IOI siempre son una amenaza para sus operaciones, la creciente opinión pública hacia la explotación de las plantaciones de palma hace que cada vez sea más dificil afrontar los desafíos propios del negocio, por lo que es necesario analizar a profundidad la organización e historia de esta "mini-multinacional" y otorgar los medios necesarios para el éxito con miras al año 2025. 


\section{CAPÍTULO I: OBJETIVOS}

\subsection{Objetivo General}

Mediante el análisis de la empresa y el contexto global de la industria, identificar oportunidades de mejora en el manejo de IOI Corporation y recomendar estrategias que impulsen el éxito de la empresa en los próximos años de manera sostenible.

\subsection{Objetivos Específicos}

a. Analizar los mercados actuales de aceite de palma e identificar nuevas oportunidades de negocio para la empresa donde se pueda expandir posteriormente.

b. Analizar la cartera de productos y el perfil de clientes para elaborar estrategias de mercadotecnia internacional, implementando un estudio interno y externo de las variables que afectan el rendimiento de sus productos.

c. Analizar las estrategias históricas y actuales de IOI, identificar oportunidades de mejora y recomendar estrategias globales acorde a los objetivos planteados al 2025.

d. Analizar el rendimiento de la cadena de suministro de IOI, identificando estrategias para la mejora continua e integración de sus unidades de negocio.

e. Analizar los estados financieros de IOI, identificar problemas y situación actual de la empresa y sugerir estrategias que garanticen estados financieros saludables y que puedan sustentar un crecimiento al año 2025. 


\section{CAPÍTULO II: PREGUNTAS DE INVESTIGACIÓN}

El siguiente caso busca resolver las siguientes preguntas preestablecidas para acceder al grado de Licenciado de la Carrera de Negocios Internacionales de la Universidad de Lima.

\section{1 Área Inteligencia de Mercados Internacionales}

Pregunta 1:

De acuerdo con Trade Map (2019), analizar los cinco principales importadores de aceite de palma y brindar una recomendación al CEO (Lee), sobre qué destino sería el más interesante para enfatizar más sus exportaciones. Tome en consideración información de Trade Map y el Banco Mundial.

\section{Pregunta 2:}

Debido a que el CEO, busca expandir sus exportaciones hacia países emergentes, seleccionar los 5 principales emergentes con base en el Ranking de variación acumulada en el año de términos porcentuales. Para el efecto, utilice el informe del 13 de marzo del 2019, que lo ubica en el siguiente link:

\section{https://www.bankiaestudios.com/estudios/es/publicaciones/monitor-de-mercados- emergentes-13-marzo-2019.html}

Pregunta 3:

Sobre la base del país emergente seleccionado, mediante el método de consumo aparente (producción + importación - exportación) determinar cuál es el tamaño de mercado. 


\section{2 Área Mercadotecnia Internacional}

Pregunta 4:

Analice los grupos de productos donde participa IOI en los mercados de países desarrollados. Para el efecto, se requiere que emplee los siguientes instrumentos:

a. Elabore una matriz de los diferentes segmentos donde participan los productos de IOI.

b. Elabore una matriz de las características del perfil de clientes industriales para cada uno de los diferentes productos que provee al mercado IOI.

c. Realice una evaluación global de la atractividad de la industria de los grupos de productos a partir de la elaboración de las matrices de las cinco fuerzas de Michael Porter, EFI Y EFE.

Pregunta 5:

Ante las denuncias presentadas por las ONGs y la crisis de sostenibilidad que enfrente IOI que pone en riesgo su crecimiento y rentabilidad, se solicita que analice la estrategia de comunicación de la empresa

a. ¿Considera usted que la empresa ha utilizado una estrategia de comunicación apropiada? Sustente técnicamente su respuesta a favor o en contra

b. Plantee tres alternativas de estrategias integrales de comunicación de IOI, utilizando los elementos de la mezcla de promoción

c. A través de la elaboración de una matriz de ranking de factores, elija la estrategia de comunicación más adecuada.

d. ¿En qué medida los resultados esperados de la estrategia integral de comunicación de IOI podría coadyuvar al Plan 2025 de la empresa? Explique.

Pregunta 6:

Elabore una estrategia de marketing para IOI teniendo en cuenta los retos que tiene su crecimiento hacia el futuro y su decisión conservadora a partir de su experiencia adquirida en los últimos años de su gestión. Incorpore en su análisis los siguientes elementos:

a. Análisis de una cartera de sus actividades. Entre las metodologías empleadas, incluya la matriz BCG 
b. Elabore y analice las estrategias básicas de desarrollo, crecimiento y competitivas que a su criterio debe emplear la empresa. ¿Está de acuerdo con las estrategias que ha venido empleando la empresa?

c. En atención a la mirada de expansión internacional que tiene la empresa, elabore y analice las estrategias de desarrollo internacional que debería seguir IOI. ¿Qué modalidades siguiere?

Pregunta 7:

IOI es una empresa familiar. Analice este tipo de gestión comercial respondiendo lo siguiente:

a. ¿Cuál es su opinión y análisis sobre las empresas familiares? Realice un FODA

b. ¿Piensa usted que IOI como empresa familiar está mejor posicionada que una empresa no familiar para lograr el crecimiento que busca globalmente IOI Loders Croklaan?

\section{3 Área Strategic Global Management}

Pregunta 8:

¿Qué factores y estrategias externas e internas permitieron que IOI creciera desde una empresa de plantaciones de palma de Malasia a una "mini-multinacional”?

\section{Pregunta 9:}

¿Con qué desafío se enfrentó el CEO (Lee) cuando IOI trató de hacer crecer su negocio IOI Loders Croklaan en diferentes continentes?

\section{Pregunta 10:}

Las ventajas competitivas a largo plazo se basan en la habilidad de obtener los beneficios de los modelos de negocios existentes y al mismo tiempo invertir en innovación para prepararse para un crecimiento. En este sentido, ¿considera que IOI ha sido exitoso? ¿Por qué sí o por qué no? 
Pregunta 11:

¿Considera que IOI, como una empresa familiar, está mejor posicionada que una empresa no familiar para hacer que el negocio de IOI Loder Croklaan se convierta en un negocio de ingredientes a base de palma, innovador y admirado a nivel mundial? ¿Por qué sí o por qué no?

\section{Pregunta 12:}

¿Debería Lee aceptar la ambiciona propuesta de Julian Veitch, CEO de los negocios derivados (downstream) de aceite de palma? ¿Qué recomendaciones adicionales tendría usted para Lee?

\section{4 Área Logística del Comercio Internacional}

Pregunta 13:

Focalizarse en el rendimiento de la cadena de suministro ayuda a proporcionar muchos beneficios directos e indirectos para IOI Group, a través de nuevas soluciones que agregan más valor a su producto. Identifique y analice tres variables que afectan el rendimiento de la cadena de suministro de IOI Corporation. ¿Qué recomendaciones daría para mejora esta situación?

\section{Pregunta 14:}

El enfoque Just-In-Time (JIT) no se incluye en los conceptos de las prácticas de SCM en la industria del aceite de palma. ¿Por qué? Explique dos razones.

\section{Pregunta 15:}

"La coordinación entre las operaciones downstream y upstream se canalizó a través de Lee como CEO del Grupo IOI, y fue el enlace esencial que supervisa todos los negocios". ¿Está de acuerdo o no? Sustente. 


\section{5 Área Financiamiento Internacional}

Pregunta 16:

Analice financieramente la empresa. ¿Cuáles son sus principales conclusiones?

Pregunta 17:

Si el CEO le ofrece pagarle con acciones de la empresa. ¿usted aceptaría? Sustente.

Pregunta 18:

¿Considera usted que las proyecciones financieras puedan cumplir la meta al 2025 considerando el apalancamiento de la empresa? ¿Fue una medida correcta el apalancamiento de la empresa?

Pregunta 19:

¿Qué aspectos financieros debe considerar la empresa para ingresar a nuevos mercados no emergentes o menos relacionados? 


\section{CAPÍTULO III: METODOLOGÍA DE RECOLECCIÓN DE LA INFORMACIÓN}

\subsection{Fuentes primarias}

Para el presente estudio se usaron las siguientes fuentes primarias de información:

- Reportes anuales de la Industria: Los reportes desde el 2002 de IOI Corp., y de sus principales competidores.

- Las publicaciones institucionales por parte del Roundtable on Sustainable Palm Oil, World Economic Forum, Banco Mundial e International Trade Centre.

- Libros con referencia teórica en las áreas a evaluar: Inteligencia Comercial, Marketing Internacional, Gestión Estratégica Global, Logística Internacional y Finanzas.

\subsection{Fuentes Secundarias}

Dentro de las fuentes secundarias, se recopilaron papers e informes académicos obtenidos de Researchgate, Social Science Research Network y Dialnet.

\subsection{Técnica de recolección de datos}

Según Hernández, Fernández y Baptista (2014) la técnica de recolección de datos es no experimental, transeccional, descriptivo, que implica la descripción de las 5 áreas a evaluar dentro del análisis de IOI Corporation (pp. 92, 152,154). 


\section{CAPÍTULO IV: METODOLOGÍA DE ANÁLISIS DE LA INFORMACIÓN}

\subsection{Enfoque del análisis}

El enfoque del análisis del contexto y estrategias de IOI Corporation será cuantitativo, debido al estudio numérico de los resultados actuales (Hernández et al., 2014, p. 36)

\subsection{Alcance del análisis}

Debido al análisis correspondiente a la industria de aceite de palma en las 5 áreas de evaluación, se implementará un análisis descriptivo, esto permitirá delimitar a las empresas por ubicación geográfica, en este caso Malasia e Indonesia (Hernández et al., 2014, p. 92) 


\section{CAPÍTULO V: DESCRIPCIÓN DEL CASO}

IOI Corporation Berhad es una empresa de alcance global en la industria del aceite de palma, ha crecido de manera dramática con una estrategia de crecimiento orgánica y adquisiciones, convirtiéndose en una "mini-multinacional" liderada por su CEO Lee Yeow Chor (Lee), con un foco en innovar y diferenciarse frente a su competencia, manteniendo control de sus costos y orientada a objetivos. Sin embargo, IOI enfrenta varios desafíos y es el momento de tomar decisiones que definirán el futuro de la empresa.

En el 2002, IOI adquierió la división de investigación y desarrollo de aceites y grasas de Unilever, Loders Croklaan, con el objetivo de expandir sus operaciones de manufactura y downstream en Europa y Norteamérica, permitiéndoles un mayor grado de innovación en sus productos. Posteriormente, Lee designo a Julian Vetch como CEO de IOI Loders Croklaan, quien ideó un plan al 2025 de doblar el volumen de venta y triplicar las utilidades. Esta integración dio oportunidades al grupo IOI, pero también supuso retos para Lee debido al tamaño en el que creció la empresa.

Eventualmente, en el 2015, la compañía enfrentó una crisis de sostenibilidad debido a utilidades estancadas, reservas consumidas y su apalancamiento financiero llegó a ser uno de los más altos de la industria; esto, combinado a fenómenos externos como el tipo de cambio más alto y el bajo rendimiento del aceite de palma debido al Fenómeno del Niño, afectaron profundamente a IOI. Por si fuera poco, en el 2016 la Roundtable on Sustainable Palm Oil (RSPO) suspendió los certificados de sostenibilidad a IOI debido a malas prácticas en plantaciones de la compañía. Esto tuvo un alcance dentro de todas sus operaciones, viendo su reputación dañada y perdiendo clientes importantes como Unilever, Kellogg Company y Nestlé.

Actualmente, IOI ha logrado sobrepasar estos desafíos, estabilizando sus estados financieros y recuperando sus certificaciones y antiguos clientes. Ahora, la compañía busca compensar los años perdidos y ha propuesto una estrategia de expansión agresiva para cumplir con el plan 2025 propuesto. Sin embargo, los recientes sucesos ponen en duda si esta sea la mejor estrategia para seguir en este momento y Lee debe decidir lo mejor para el negocio familiar. 


\section{CAPÍTULO VI: ANÁLISIS Y DISCUSIÓN DE RESULTADOS}

\section{1 Área Inteligencia de Mercados Internacionales}

El análisis de esta área es imperativo para lograr un entendimiento de que decisiones se pueden tomar en base a la situación actual de los mercados internacionales, esto es indudablemente importante para el caso de IOI Group, que necesita tomar decisiones sobre sus exportaciones y operaciones internacionales, considerando una expansión o redireccionar sus productos actuales. Para esto, se ha analizado a los principales importadores de aceite de palma, por lo que llegamos a la siguiente información.

En primer lugar, se encontró que los 5 principales países importadores de aceite de palma fueron India, China, Pakistán, Holannda y España. A estos países se les ha evaluado a través de la metodología del Ranking de factores, dando una calificación del 1 al 5 ( 1 representa el menor puntaje y 5 el mayor puntaje) sobre diferentes criterios para definir su competitividad y viabilidad de exportación, usando data correspondiente a Trade Map (2019) y del Banco Mundial (2019)

Bajo ese análisis, vemos que en los criterios de volumen de mercado, India y China se perfilan como candidatos enfocar las exportaciones de IOI Group debido a su alto volumen de importaciones de aceite de palma, sin embargo el nivel de precios que ofrece Países Bajos y España hace que se consiga una mayor rentabilidad y beneficio para la empresa, a pesar de que no importan en la misma cantidad que los países anteriores. En indicadores macroeconómicos, Holanda y España vuelven a ser los países más competitivos en todos los criterios, a excepción del crecimiento anual de sus PBI. 
Tabla 6.1

Ranking de Factores de los 5 principales países importadores de aceite de palma

\begin{tabular}{|c|c|c|c|c|c|c|c|}
\hline Criterio & Año & Peso & India & China & Pakistán & Holanda & España \\
\hline VOLÚMEN DE COMERCIO & 2018 & $30 \%$ & & & & & \\
\hline Volumen de importaciones & 2018 & $15 \%$ & 5 & 4 & 3 & 2 & 1 \\
\hline Nivel de precios de importaciones & 2018 & $15 \%$ & 1 & 2 & 3 & 5 & 4 \\
\hline INDICADORES MACROECONÓMICOS & $2018 / 17$ & $20 \%$ & & & & & \\
\hline Facilidad para hacer negocios & 2018 & $10 \%$ & 2 & 3 & 1 & 4 & 5 \\
\hline Crecimiento PBI (anual \%) & 2017 & $5 \%$ & 5 & 4 & 3 & 1 & 2 \\
\hline Exportaciones de productos y servicios & 2017 & $2.50 \%$ & 2 & 3 & 1 & 5 & 4 \\
\hline Importaciones de productos y servicios & 2017 & $2.50 \%$ & 3 & 2 & 1 & 5 & 4 \\
\hline INDICADORES DESEMPEÑO LOGISTICO & 2018 & $40 \%$ & & & & & \\
\hline Desempeño Logístico: General & 2018 & $10 \%$ & 2 & 3 & 1 & 5 & 4 \\
\hline $\begin{array}{l}\text { Frecuencia con la que los embarques llegan al consignatario en el } \\
\text { tiempo programado }\end{array}$ & 2018 & $5 \%$ & 2 & 3 & 1 & 5 & 4 \\
\hline Habilidad para rastrear y localizar envíos & 2018 & $5 \%$ & 2 & 3 & 1 & 5 & 4 \\
\hline Facilidad de disponer envíos con precios competitivos & 2018 & $5 \%$ & 2 & 3 & 1 & 4 & 5 \\
\hline Eficiencia del proceso de despacho de aduanas & 2018 & $5 \%$ & 2 & 3 & 1 & 5 & 4 \\
\hline Competencia y calidad de los servicios logísticos & 2018 & $5 \%$ & 2 & 3 & 1 & 5 & 4 \\
\hline Calidad de la infraestructura de comercio y transporte & 2018 & $5 \%$ & 2 & 3 & 1 & 5 & 4 \\
\hline OTROS INDICADORES & 2018 & $10 \%$ & & & & & \\
\hline Tiempo de importación: cumplimiento documental (horas) & 2018 & $5 \%$ & 2 & 3 & 1 & 5 & 5 \\
\hline Costo para importar, cumplimiento fronterizo (US\$) & 2018 & $5 \%$ & 2 & 3 & 1 & 5 & 5 \\
\hline
\end{tabular}

Fuente: Banco Mundial (2019). International Trade Center (2019).

Elaboración propia. 
Finalmente, en indicadores logísticos y de desempeño, estos países vuelven a ser dominantes de estas categorías, definiéndose Países Bajos como el país con mayores beneficios para exportar aceite de palma, con un puntaje de 4.2.

Luego, se hizo el mismo tipo de evaluación y metodología del Ranking de factores, esta vez incluyendo los 5 principales países emergentes (tabla 6.3), determinados en el informe de Bankia Estudios (2019), el resultado incluyó a Grecia, Colombia, Vietnam, Egipto y Brasil. Este analisis fue concluyente para determinar qué país es el más atractivo entre los emergentes para enfocar esfuerzos y recursos por parte de IOI Group y diversificar los mercados en donde comercializa sus productos. Durante toda la evaluación, Vietnam se mostró consistente en todos los criterios de evaluación, siendo el país que muestra mayor competitividad y mejor prospecto, solo no destaca en el precio de importación que representan el menor beneficio en cuanto a ingreso para IOI Group. Con esto, Vietnam alcanza un puntaje de 3.95, siendo el mejor dentro de este análisis, considerando su volumen de comercio, indicadores macroeconómicos y desempeño logístico. Habiendo seleccionado a Vietnam, se procedió a determinar el tamaño de mercado de este país a través del método de consumo aparente, el cual consiste en sumar el total de su producción nacional y sus importaciones, para luego sustraer el total de sus exportaciones, esto en términos de miles de toneladas

Tabla 6.2

Tamaño de mercado de Vietnam en miles de toneladas

CRITERIO 2016

Producción

Exportación $\quad 55,862$

Importación $\quad 594,731$

Total $\quad \mathbf{5 3 8 , 8 6 9}$

Fuente: ITC (2019). FAO (2019)

Elaboración propia. 
Tabla 6.3

Ranking de Factores de principales países emergentes

\section{Criterio}

Año Peso Grecia Colombia Vietnam Egipto Brasil

VOLÚMEN DE COMERCIO

Volumen de importaciones

Nivel de precios de importaciones

INDICADORES MACROECONÓMICOS

Facilidad para hacer negocios

Crecimiento PBI (anual \%)

Exportaciones de productos y servicios

Importaciones de productos y servicios

2018

\begin{tabular}{ll|lllll|}
2018 & $15 \%$ & 1 & 3 & 5 & 4 & 2
\end{tabular}

INDICADORES DESEMPEÑO LOGISTICO

Desempeño Logístico: General

Frecuencia con la que los embarques llegan al consignatario en el tiempo programado

Habilidad para rastrear y localizar envíos

Facilidad de disponer envíos con precios competitivos

Eficiencia del proceso de despacho de aduanas

Competencia y calidad de los servicios logísticos

Calidad de la infraestructura de comercio y transporte

OTROS INDICADORES

Time to import, documentary compliance (hours)

Cost to import, border compliance (US\$)

2018

$15 \%$

4

$2018 / 17 \quad 20 \%$

$\begin{array}{cc}2018 & 10 \% \\ 2017 & 5 \%\end{array}$

$2017 \quad 5 \%$

$\begin{array}{ll}2017 & 2.50 \% \\ 2.50 \%\end{array}$

$\begin{array}{lllll}3 & 5 & 4 & 1 & 2 \\ 2 & 3 & 5 & 4 & 1\end{array}$

23

2

$2018 \quad 40 \%$

4

Fuente: Banco Mundial (2019). International Trade Center (2019).

Elaboración propia. 
Para esto, se usó data extraída por la Organización de las Naciones Unidas para la Alimentación y la Agricultura (FAO, 2019) al año 2016 y de Trademap (2019). Esta busqueda arrojó que Vietnam no es productor de aceite de palma, teniendo un volumen de producción de 0 Tn. Por otro lado, el país importó 594,731 Tn en el año 2016, a esto se le sustrae las exportaciones del año en aceite de palma, que alcanzaron las 55,862 Tn, haciendo un tamaño total de mercado de 538,869 Tn.

\section{2 Área Mercadotecnia Internacional}

Para el estudio del área de Marketing internacional, se han tenido en cuenta para el análisis estratégico la cartera de productos que ofrece IOI Group, los perfiles de los clientes de la empresa, así como también un análisis de la industria a nivel global.

Para la evaluación de la cartera de productos de IOI Group, se elaboró una matriz de diferenciación de los segmentos donde estos participan (tabla 6.4).

Según los reportes anuales de IOI y la información disponible sobre sus productos, se identificaron cuatro segmentos de los que el grupo considera como divisiones de negocio diferentes: la venta del aceite de palma crudo y aceite de palma Kernel, la venta y exportaciones de aceites, grasas especializadas y oleo químicos, esta última tiene además la función de proveer a IOI de materias primas para la manufactura de productos con mayor valor agregado y mayor grado de refinación, por lo que de esta surgen otros 2 segmentos como lo son los aceites y grasas especializados en la industria alimenticia, y los oleo químicos, dirigido a las industrias de cuidado personal, productos para el hogar, farmacéuticos y aplicaciones tecnológicas. 
Tabla 6.4

Matriz de diferenciación de segmentos y productos de IOI

\begin{tabular}{|c|c|c|c|c|}
\hline \begin{tabular}{c|} 
SEGMENTOS \\
GRUPO IOI \\
\end{tabular} & \multicolumn{2}{|c|}{ SEGMENTOS } & INDUSTRIAS & PRODUCTOS / MARCAS \\
\hline \multirow{6}{*}{$\begin{array}{l}\text { Aceite de } \\
\text { palma crudo y } \\
\text { aceite de palma } \\
\text { Kernel }\end{array}$} & \multicolumn{2}{|c|}{$\begin{array}{l}\text { Aceite de palma crudo y aceite de palma Kernel: Venta y exportación } \\
\qquad \text { (segmento 1) }\end{array}$} & \multicolumn{2}{|c|}{$\begin{array}{l}\text { En el segmento de operaciones continuas, la venta y exportación de } \\
\text { aceite de palma crudo representa el } 63 \% \text { de ingresos del segmento, y } \\
\text { el } 79 \% \text { del segmento de operaciones discontinuas }\end{array}$} \\
\hline & \multirow{5}{*}{$\begin{array}{l}\text { Refinería: venta y exportación de } \\
\text { aceites, grasas especializados y oleo } \\
\text { químicos (segmento 2) }\end{array}$} & $\begin{array}{l}\text { Aceites y grasas especializados: } \\
\text { Surte de materia prima a IOI para } \\
\text { crear productos de la siguiente } \\
\text { industria (segmento } 3 \text { ) }\end{array}$ & Alimentos & $\begin{array}{c}\text { Ofrecen grasas saborizadas, } \\
\text { emulsiones, aceites especiales y } \\
\text { edibles de marca: Witocan, } \\
\text { Witarix, Dynacet, Spezialol, entre } \\
\text { otras }\end{array}$ \\
\hline & & \multirow{4}{*}{$\begin{array}{l}\text { Oleo químicos: Surte de materia } \\
\text { prima para crear productos de la } \\
\text { empresa en las siguientes } \\
\text { industrias (segmento } 4 \text { ) }\end{array}$} & Cuidado personal y cosméticos & $\begin{array}{l}\text { Cuidado de la piel, cabello, del sol y } \\
\text { productos para bebe a través de: } \\
\text { Dynasan, Imwitor, Miglyol, } \\
\text { Softigen. }\end{array}$ \\
\hline & & & Productos para el hogar & $\begin{array}{c}\text { Sus insumos se usan en detergentes } \\
\mathrm{y} \text { tratamiento de agua }\end{array}$ \\
\hline & & & Farmacéuticos & $\begin{array}{c}\text { Compuestos Witepsol, Softisan y } \\
\text { Miglyol }\end{array}$ \\
\hline & & & Aplicaciones tecnológicas & $\begin{array}{l}\text { Aditivos Softenol como lubricantes, } \\
\text { polietileno, anti-condensadores, etc }\end{array}$ \\
\hline
\end{tabular}

Fuente: Annual Reports IOI Group (2019). IOI Group Web (2019).

Elaboración propia 
Tabla 6.5

Matriz de Perfil de Clientes de IOI

\begin{tabular}{|c|c|c|c|c|c|c|c|}
\hline \multirow{3}{*}{$\begin{array}{c}\text { IOI } \\
\text { Clientes/Productos } \\
\text { (Países } \\
\text { Desarrollados) }\end{array}$} & \multirow{3}{*}{$\begin{array}{c}\text { Aceites Palma } \\
\text { y Kernel crudo } \\
\text { S1: } \\
\text { Plantaciones }\end{array}$} & $\begin{array}{c}\text { Aceites alimenticios (grasas } \\
\text { saborizadas y aceites } \\
\text { especiales) }\end{array}$ & $\begin{array}{l}\text { Aceites cuidado } \\
\text { personal }\end{array}$ & $\begin{array}{c}\text { Insumos } \\
\text { detergentes y } \\
\text { tratamiento de } \\
\text { agua } \\
\end{array}$ & $\begin{array}{c}\text { Insumos } \\
\text { Farmacéuticos }\end{array}$ & Aditivos y lubricantes & Biodiesel \\
\hline & & \multicolumn{6}{|c|}{ S2: Refinería } \\
\hline & & $\begin{array}{c}\text { S3: Aceites y grasas } \\
\text { especializados }\end{array}$ & \multicolumn{5}{|c|}{ S4: Oleo-químicos } \\
\hline \multicolumn{8}{|c|}{ Variables Demográficas } \\
\hline $\begin{array}{c}\text { Industria de las } \\
\text { empresas }\end{array}$ & $\begin{array}{l}\text { Todas las } \\
\text { industrias }\end{array}$ & Alimentos & $\begin{array}{c}\text { Cosméticos e } \\
\text { higiene personal }\end{array}$ & Limpieza del hogar & Farmacéutica & $\begin{array}{l}\text { Automotriz y } \\
\text { tecnología }\end{array}$ & Automotriz \\
\hline $\begin{array}{l}\text { Tamaño de las } \\
\text { Empresas }\end{array}$ & $\begin{array}{l}\text { Medianas y } \\
\text { Grandes }\end{array}$ & Grandes & Grandes & $\begin{array}{l}\text { Medianas y } \\
\text { Grandes }\end{array}$ & Grandes & Grandes & $\begin{array}{c}\text { Medianas y } \\
\text { Grandes }\end{array}$ \\
\hline \multicolumn{8}{|c|}{ Variables Operativas } \\
\hline Tecnología & $\begin{array}{l}\text { Insumos y } \\
\text { productos }\end{array}$ & Insumo producción & $\begin{array}{l}\text { Insumo } \\
\text { producción }\end{array}$ & Insumo producción & $\begin{array}{l}\text { Insumo } \\
\text { producción }\end{array}$ & Insumo producción & $\begin{array}{c}\text { Insumo } \\
\text { producción }\end{array}$ \\
\hline $\begin{array}{l}\text { Condiciones de } \\
\text { Usuario }\end{array}$ & $\begin{array}{l}\text { Medios y } \\
\text { esporádicos }\end{array}$ & Frecuentes & Frecuentes & Frecuentes & Frecuentes & Frecuentes & $\begin{array}{l}\text { Medios y } \\
\text { esporádicos }\end{array}$ \\
\hline $\begin{array}{l}\text { Capacidad de los } \\
\text { clientes }\end{array}$ & Pocos servicios & Muchos servicios & Muchos servicios & Muchos servicios & $\begin{array}{l}\text { Muchos } \\
\text { servicios }\end{array}$ & Muchos servicios & $\begin{array}{l}\text { Pocos } \\
\text { servicios }\end{array}$ \\
\hline
\end{tabular}

Continúa 
(continuación)

Factores y Proceso de compra

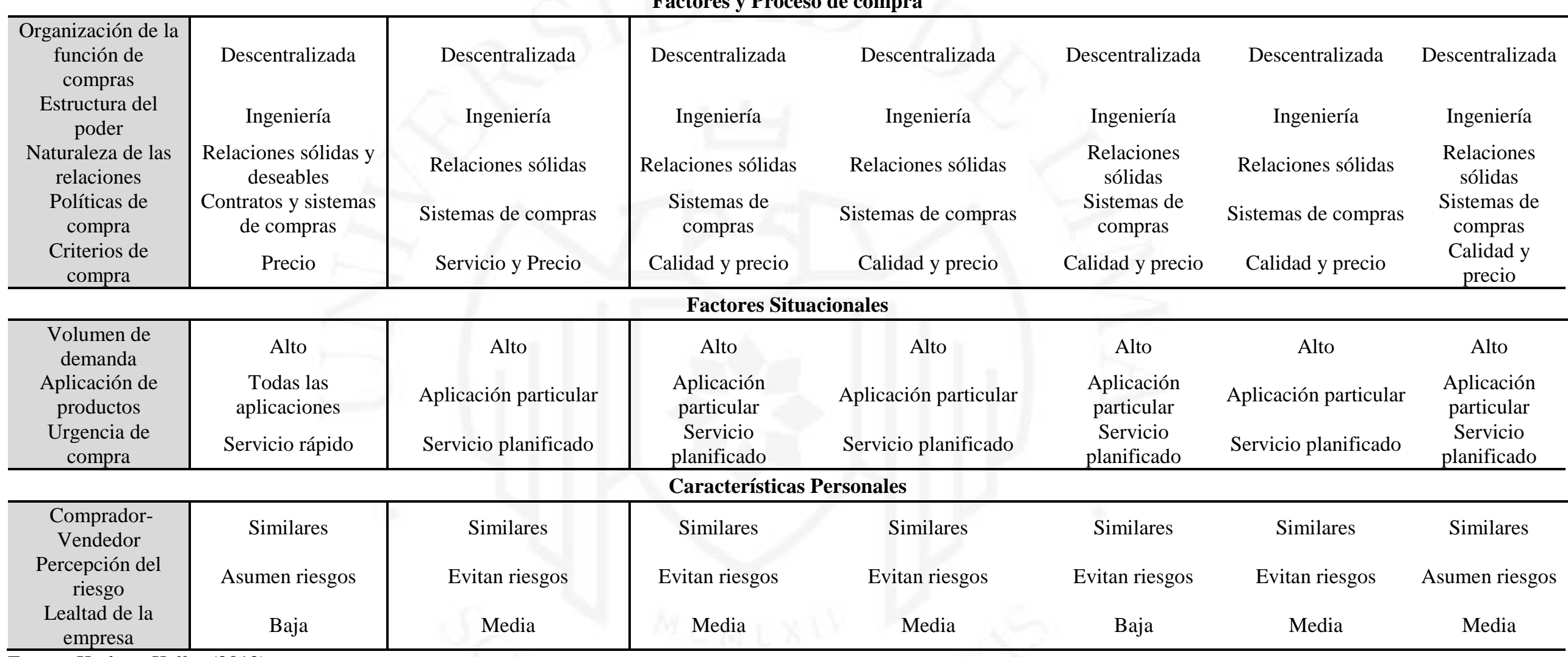

Fuente: Kotler y Keller (2012)

Nota: Elaboración Propia 
Posteriormente, también se realizó una matriz de características del perfil de clientes del grupo IOI (tabla 6.5), para esto se usó el modelo de segmentación de mercados industriales de Shapiro y Bonoma (1984, párr. 9), el llamado "Enfoque Nido" debido a que identificaron 5 criterios generales de segmentación y los ordenaron de esa forma, teniendo como criterios demografía, un criterio amplio y simple de extraer en cualquier industria o mercado, hasta las características personales de cada empresa, un criterio mucho más específico y sutíl (Shapiro y Bonoma, 1984). Los criterios son: demografía, variables operativas, factores y procesos de compra, factores situacionales y las características personales del cliente. El contenido fue elaborado en base a un análisis personal de las características de los clientes de IOI.

Figura 6.1

Enfoque de Nido de Shapiro y Bonoma

Nested Approach

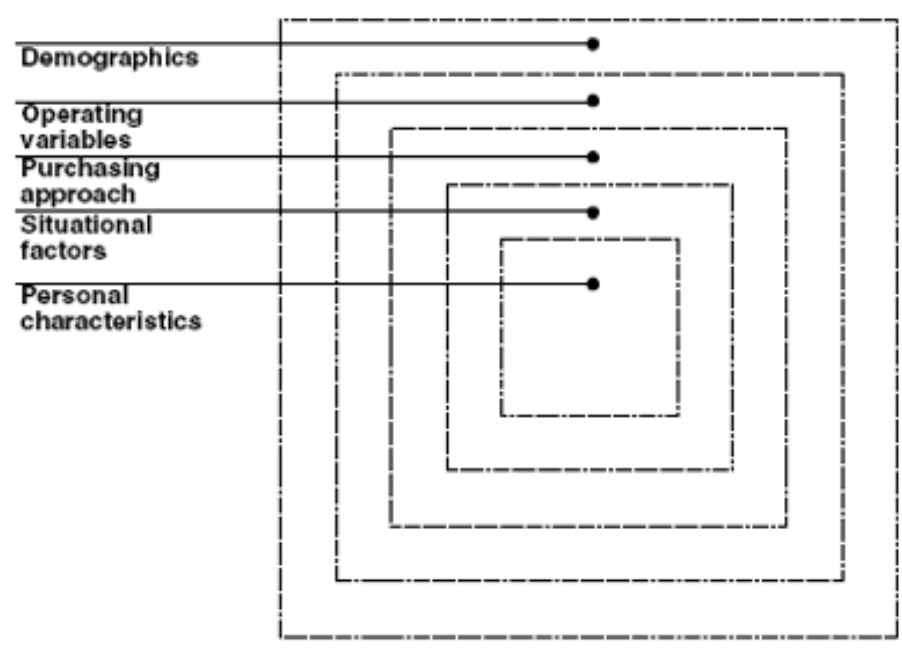

Fuente: Shapiro y Bonoma (2019)

Al mismo tiempo, se realizaron las matrices de análisis de factores externos (ver tabla 6.6), internos (tabla 6.7) y de las cinco fuerzas de Porter (tabla 6.8) para evaluar la atractividad global de las industrias donde IOI tiene presencia, para este análisis hay que tener en cuenta que se dará puntaje a cada criterio de factores, siendo el máximo puntaje 4 y el menor 1, el 4 indicando si una empresa está mejor preparada para aprovechar una oportunidad o si se trata de ventaja mayor de la empresa, por el contrario el puntaje 1 
significaría una debilidad mayor o una amenaza que la empresa no puede responder de forma eficiente (David, 2013). El puntaje promedio de las calificaciones posibles es 2.5, esta es la mínima calificación que una empresa tiene que obtener para poder afirmar que está preparada para competir en su entorno.

Pasando a la evaluación de las matrices, la de análisis de factores externos. Para esta tabla, se toman en cuenta factores referentes a las oportunidades y amenazas que puede enfrentar la empresa, teniendo como puntuación final 2.53, lo que significa que la empresa está en condiciones de afrontar las amenazas existentes en la industria aprovechando adecuadamente las oportunidades, esta puntuación significa que la empresa responde de manera correcta ante su entorno, pero no sobresaliente. Luego, se analizaron los factores internos de la empresa mediante una matriz que califica debilidades y fortalezas, en esta ocasión IOI consiguió un puntaje de 2.56, esto quiere decir que la empresa está en condiciones de afrontar sus debilidades de manera adecuada usando sus fortalezas, aunque no de una manera eficiente y eficaz.

Para culminar este análisis, se elaboró una matriz de las cinco fuerzas de Porter. En este análisis se obtuvo los siguientes resultados, evaluando la amenaza de nuevos competidores y de productos sustitutos, el poder de negociación con proveedores y clientes y la rivalidad de competidores en la industria donde IOI participa. 
Tabla 6.6

\section{Matriz de Factores Externos}

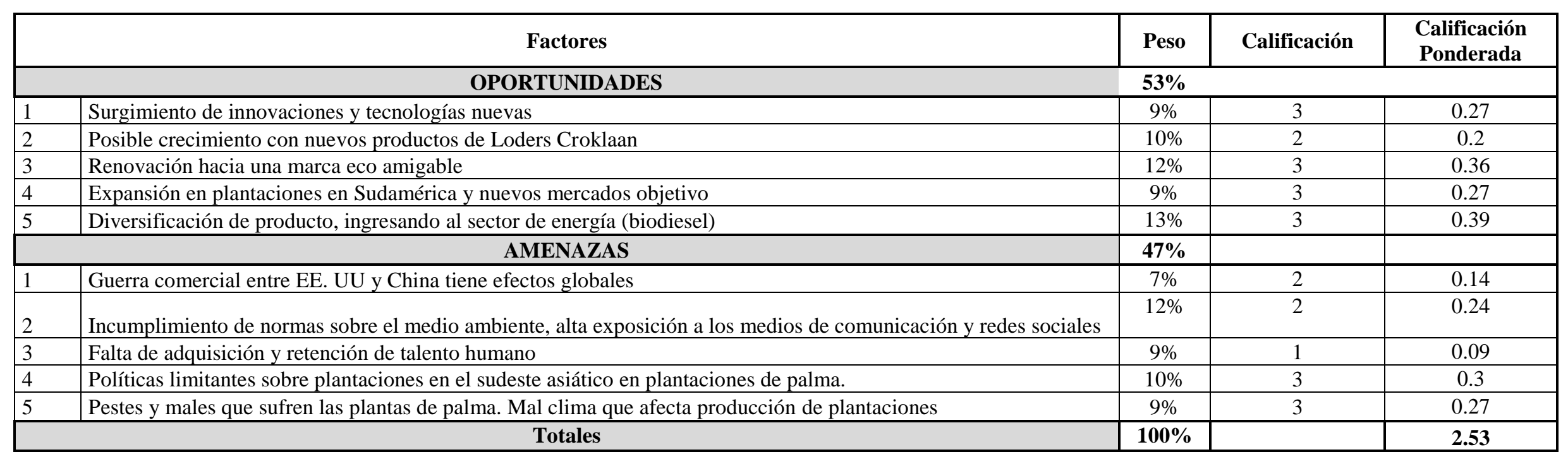

Elaboración propia 
Tabla 6.7

Matriz de Factores Internos

\begin{tabular}{|c|c|c|c|c|}
\hline \multicolumn{2}{|r|}{ Factores } & Peso & Calificación & Calificación \\
\hline \multicolumn{2}{|r|}{ Debilidades } & \multicolumn{3}{|l|}{$46 \%$} \\
\hline 1 & $\begin{array}{l}\text { Bajos niveles de integración y retroalimentación entre las operaciones por países. Cada una se maneja de manera individual } \\
\text { y poca integración de estrategias }\end{array}$ & $12 \%$ & 1 & 0.12 \\
\hline 2 & Competencia posee más hectáreas plantadas. Mayor materia prima & $6 \%$ & 2 & 0.12 \\
\hline 3 & Tasa de apalancamiento alta & $10 \%$ & 1 & 0.10 \\
\hline 4 & Cuellos de botella en la oferta en Norte America, utilización de plantas no óptima & $8 \%$ & 2 & 0.16 \\
\hline \multirow[t]{2}{*}{5} & Conservadurismo y poca decisión de acción. Todas las decisiones deben tener aprobación ejecutiva & $10 \%$ & 1 & 0.10 \\
\hline & Fortalezas & \multicolumn{2}{|l|}{$\mathbf{5 4 \%}$} & \\
\hline 1 & Gran cartera de productos, procesos y aplicaciones innovadoras bajo RyD & $12 \%$ & 4 & 0.48 \\
\hline 2 & Estado financiero en buen estado & $12 \%$ & 3 & 0.36 \\
\hline 3 & "Customer centered approach" por parte de IOI Group & $10 \%$ & 4 & 0.40 \\
\hline 4 & Cadena de suministro renovada & $12 \%$ & 4 & 0.48 \\
\hline \multirow[t]{2}{*}{5} & Imagen y reputación de marca. Es reconocida a pesar de sus fallas pasadas & $8 \%$ & 3 & 0.24 \\
\hline & Totales & $100 \%$ & & 2.56 \\
\hline
\end{tabular}

Elaboración propia 
Tabla 6.8

Matriz de las 5 fuerzas de Michael Porter

\begin{tabular}{|c|c|c|}
\hline & $\begin{array}{c}\text { 1. Amenaza de Nuevos Competidores } \\
\text { Bajo: Ingresar a la industria de plantación y refinamiento de } \\
\text { aceite de palma requiere una gran inversión financiera por la } \\
\text { adquisición de propiedad, además de la construcción de las } \\
\text { plantas industriales para el refinamiento del producto. A su vez, } \\
\text { políticas se van endureciendo, haciendo difícil el ingreso de más } \\
\text { empresas. }\end{array}$ & \\
\hline \multirow[t]{2}{*}{$\begin{array}{l}\text { 3.Amenaza de Productos Sustitutos } \\
\text { Medio: Cada vez se investigan e ingresan al } \\
\text { mercado nuevos productos que pueden suplir } \\
\text { al aceite de palma, sin embargo la flexibilidad } \\
\text { y versatilidad que otorga como insumo en } \\
\text { productos variados y bajos costos, hacen } \\
\text { dificil su reemplazo. }\end{array}$} & $\begin{array}{l}\text { 5. Rivalidad de competidores } \\
\text { Medio: la industria de aceite de palma se encuentra bastante } \\
\text { fraccionada, hay un gran número de empresas relacionadas a la } \\
\text { oferta que tiene IOI y la industria cuenta con al menos } 7 \\
\text { empresas líderes y altamente competitivas a nivel global. Es muy } \\
\text { improbable que este status quo cambie }\end{array}$ & $\begin{array}{l}\text { 4. Poder de Negociación con Proveedores } \\
\text { Medio: Aunque IOI se provee materia prima, } \\
\text { cuenta con proveedores que cumplen con otras } \\
\text { tareas tales como transporte y sostenibilidad. Para } \\
\text { estas negociaciones, el tamaño de IOI no } \\
\text { representa un gran beneficio. Algunos proveedores } \\
\text { incluso son de la misma talla }\end{array}$ \\
\hline & $\begin{array}{l}\text { 2. Poder de Negociación con Clientes } \\
\text { Medio: Debido a la gran cartera de productos de IOI, la empresa } \\
\text { tiene una cantidad de clientes. Su "customer approach" hacen } \\
\text { que sus productos tengan valor agregado y refleja en el poder de } \\
\text { negociación con sus clientes. Sin embargo, algunos de estos } \\
\text { tienen presencia internacional, como Unilever o Kellog, teniendo } \\
\text { un poder de negociación medio ante ellos. }\end{array}$ & 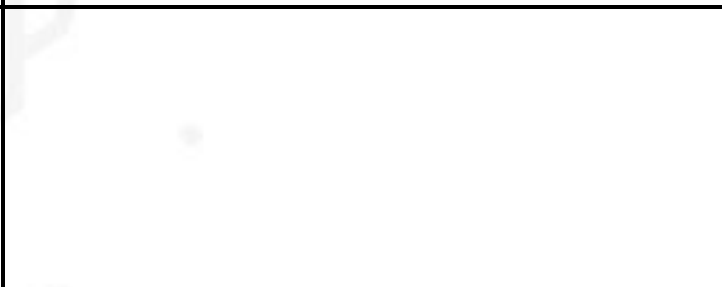 \\
\hline
\end{tabular}

Fuente: IOI Group (2019), Astra Agro Lestari (2019), Golden Agri-Resources Limited (2019), Indofood TBK (2019), Felda Globe (2019), Kuala Lumpur Kepong Berhad (2019), Wilmar International (2019). Ming y Chandramohan (2002).

Nota: Elaboración Propia 
Posteriormente, se dirigió el análisis hacia la crisis de sostenibilidad que enfrentó IOI durante el periodo 2015 - 2017. En esta crisis, la organización Aidenvironment reportó 5 principales acusaciones hacia las operaciones de IOI, aludiendo que tenían un impacto negativo hacia el medio ambiente, estas acusaciones (Roundtable on Sustainable Palm Oil, 2019), aunque aún no formalizadas y expresadas a través de una carta y declaración hacia el Roundtable on Sustainable Palm Oil fueron:

1. El rompimiento de los compromisos sostenibles de IOI Group debido a la rápida expansión de la plantación Bumi Sawit Sejahtera (PT BSS), en la isla occidental de Indonesia. Esto era una falta grave ante los compromisos efectuados al momento de integrar la Roundtable on Sustainable Palm Oil (RSPO).

2. Una zona de Alto Valor de Conservación (HCV) se perdió durante la plantación de PT BSS en el 2014, rompiendo una vez más con los compromisos efectuados por IOI.

3. Como respuesta, IOI firmó un Proyecto de Restauración de Turba. Sin embargo, IOI siguió talando bosques con el objetivo de aumentar el área efectiva de plantación de PT BSS.

4. A pesar del compromiso público de detener esta deforestación a lo largo del 2014, estas acciones siguieron fomentándose en IOI en PT BSS.

5. Por último, la plantación de IOI Berkat Nabati Sawit cometió un acto ilegal de ocupación de bosques.

Se debe considerar que como decisión final, RSPO decidió a favor de Aidenvironment (2019), luego de que esta última organización hiciera las quejas formales ante el ente correspondiente de solución de quejas del RSPO, teniendo como consecuencia la suspensión de IOI Group del Certification of Sustainable Palm Oil (CSPO) (RSPO, 2019), además de desarrollar planes de acción sostenibles para la reforestación y restauración de las áreas afectadas, también tomar medidas compensatorias con los afectados y presentar este plan en un tiempo "retador".

Cabe preguntarse, ¿por qué se llegó a esto? En un principio, las quejas no se habían formalizado y el deseo de Aidenvironment era remediar el problema sin recurrir a una disputa (Aidenvironment, 2019), sin embargo decidió realizar las quejas formales debido al poco compromiso que mostró IOI en resolver los problemas, debido a un plan de acción lento y poco retador, con primeras acciones 7 meses después de haber recibido 
la primera carta de atención sobre estos factores (Roundtable on Sustainable Palm Oil, 2019). IOI se concentró en demostrar su inocencia falsamente, debido a que era en todas circunstancias, culpable de las alegaciones en su contra y decidió ineficazmente sobre cómo proceder ante esta crisis.

Según Kotler y Keller (2012), hay varios factores que determinan la efectividad con la que un mensaje es transmitido hacia el público, estos factores serán analizados uno por uno para determinar que medios se usaron por IOI e identificar porqué su estrategia no fue correcta.

En primer lugar, se determinó que el tipo de comunicación usada por IOI fue la de Relaciones Públicas, la cuál se determina por programas dirigidos a un público interno, o en este caso un público externo que pueden ser empresas, el gobierno, entidades $\mathrm{u}$ organizaciones con el objetivo de promover o proteger la imagen de la empresa o sus productos. En este caso, se considera que la estrategia fue moderadamente correcta, debido a que IOI se vió afectada principalmente por la suspensión de su certificación, lo cual le hizo perder clientes de talla mundial e imagen de marca, si bien falló, este tipo de comunicación escogida era la correcta para solucionarlo, mediante cartas y oficios intercambiados entre la empresa, RSPO y sus clientes (Nestlé, 2018) (Unilever, 2017). Tal ves, le faltó combinar este tipo de comunicación con un marketing directo, en el cuál pueda llegar a los consumidores finales y no ver su marca deteriorada por la opinión pública, lo que en definitiva impulsó a las empresas a tomar acciones en contra de IOI. Esto va acorde con los pasos de un desarrollo de comunicación eficaz (Kotler y Keller, 2012) en el cual la indentificación del público meta es una primera etapa; en este caso, ya se identificó que IOI no se dirigió a todos los interesados de esta crisis.

En segundo lugar, tenemos la identificación de objetivos, en la que se entiende que por el actuar de IOI, el objetivo fue demostrar su inocencia a pesar de las innumerables pruebas en su contra, por lo que decidió mantener la crisis lo más reservada posible y sin desarrollar un plan de acción eficaz y compensatorio por los daños efectuados. Se esperó hasta el último instante para estar de acuerdo en que eran culpables, su poca determinación en resolver el problema desde un inicio los llevo a la suspensión del certificado de sostenibilidad.

Por último, otro factor importante en este caso es la elección del canal de comunicación, el cual no fue el correcto debido a que se limitó a comunicaciones privadas o publicas pero enfocandose meramente en los principales protagonistas de la crisis, no 
hubo una comunicación participativa con el público en general, a través de redes sociales o medios de comunicación, si no que se mantuvieron en reserva respondiendo únicamente por manera escrita ante los demandantes y la organización mediadora. Esto ocasionó otro problema más en la crisis que enfrentaron.

En base a estos errores y la estrategia de comunicación desenfocada, se ha planteado otras 3 alternativas que podrían complementar las operaciones de IOI de manera correcta, cabe resaltar que todas estas estrategias tienen que tener como base, la acción eficaz e inmediata, en la que se reconoce la culpa de las acusaciones y desarrollar acciones para contrarrestar los efectos negativos de esta crisis, protegiendo la marca lo más posible y al mismo tiempo dar a conocer y dar la percepción que la empresa desea cambiar, mejorar y tomar esto como una oportunidad de mejora:

1. Estrategia de comunicación de Relaciones Públicas, teniendo como público objetivo a las organizaciones demandantes, clientes, mediadores y público en general, con la meta de proteger la imagen de marca a través de publicaciones, relaciones con las comunidades afectadas, seminarios y discursos informativos públicos, incluso tomar en cuenta donaciones a los afectados. Para esto, sería necesario usar los medios de comunicación para transmitir su mensaje.

2. Estrategia de comunicación de Publicidad, considerando al mismo público objetivo y meta de la primera estrategia, pero enfocándose en un marketing directo y más enfocado a la opinión pública, mediante anuncios impresos y transmitidos en las zonas de Indonesia afectadas, promoción informativa sobre la crisis en lugares de alta concurrencia en donde se usan sus productos como insumos, estos podrían ser cines, gasolineras, supermercados.

3. Estrategia de comunicación de Promoción de Ventas, teniendo en cuenta el mismo público objetivo y metas, pero enfocándose en actividades promoción mezcladas con información relevante y actualizada sobre los planes de acción que se consideran para minimizar los daños y riesgos. Esto se haría a través de concursos, juegos, ferias, exposiciones y exhibiciones, trabajando en conjunto con sus clientes para fortalecer las alianzas establecidas y dar la percepción de un frente unido, además de mejorar la percepción del público en general.

Para evaluar que estrategia es la más adecuada, se realizó un ranking de factores en el que se midió los siguientes aspectos que evalúan los programas de marketing y 
comunicaciones de empresas según Keller (2013) son cobertura, contribución, ordinareidad, complementareidad, versatilidad y el costo del programa.

Tras esto, se identificó que la mejor estrategia era la de Relaciones Públicas con un puntaje de 2.00, evaluando según los criterios, las características de cada estrategia. Teniendo en cuenta esto, y en miras al plan 2025 de la empresa, se puede afirmar que tiene una relación directamente positiva con los objetivos que se desean cumplir, sobre todo teniendo en cuenta los aspectos más importantes y que otorgan mayor valor de esta evaluación. Esta estrategia de Relaciones Públicas otorgaría una estrategia de comunicación exclusiva y participativa para IOI, que permitirá proteger y mejorar la imagen de la empresa asi como sus ventas. Por otro lado, es una estrategia que es flexible en cuanto a la información que se puede brindar, así como los medios más adecuados para la publicidad y canal de comunicación de IOI. Si a esto se le añade el hecho de que es la estrategia que significa menores costos, se entiende que es la adecuada para un crecimiento orgánico de la empresa, lo cual consta de mucha inversión, por lo que tener un menor gasto también va acorde con un plan financiero saludable que actualmente se encuentra bastante apalancado. 
Tabla 6.9

Ranking de Factores de Estrategia de Comunicaciones

\begin{tabular}{|c|c|c|c|c|}
\hline Criterio & Peso & Relaciones Públicas & Publicidad & Promoción de ventas \\
\hline Cobertura & $20 \%$ & & & \\
\hline Llegada de la estrategia de comunicación & $10 \%$ & 2 & 1 & 3 \\
\hline Exclusividad de la estrategia de comunicación & $10 \%$ & 3 & 2 & 1 \\
\hline Contribución & $15 \%$ & & & \\
\hline Crear conciencia & $3.75 \%$ & 1 & 2 & 3 \\
\hline Mejorar la imagen & $3.75 \%$ & 3 & 2 & 1 \\
\hline Obtener respuestas & $3.75 \%$ & 3 & 1 & 2 \\
\hline Inducir ventas & $3.75 \%$ & 1 & 2 & 3 \\
\hline Cosas en Común & $15 \%$ & & & \\
\hline Transmisión del mismo mensaje en cualquier medio & $7.5 \%$ & 2 & 3 & 1 \\
\hline Crear una imagen de marca consistente y cohesiva & $7.5 \%$ & 1 & 3 & 2 \\
\hline Complementariedad & $15 \%$ & & & \\
\hline Las opciones de comunicación son compensatorias & $7.5 \%$ & 3 & 1 & 2 \\
\hline Crear estructuras de conocimiento en el consumidor & $7.5 \%$ & 2 & 3 & 1 \\
\hline Versatilidad & $15 \%$ & & & \\
\hline Cumple provisión de información múltiple & $7.5 \%$ & 2 & 3 & 1 \\
\hline Cumple provisión de información amplia & $7.5 \%$ & 2 & 3 & 1 \\
\hline Costo & $10 \%$ & & & \\
\hline Costo de estratégia más efectiva & $5 \%$ & 3 & 2 & 1 \\
\hline Costo de estratégia más eficiente & $5 \%$ & 3 & 1 & 2 \\
\hline
\end{tabular}

Fuente: Dirección de Marketing. Kotler y Keller (2012). Strategic Brand Manager. Keller (2019). 
En ese sentido, también se ha analizado la cartera de actividades de IOI, elaborando las siguientes matrices, para luego proceder a identificar estrategias que estén relacionadas con la situación que requiere la empresa según David (2013):

- Boston Consulting Group

Esta matriz desarrollada por la empresa del mismo nombre tiene el objetivo de identificar la tasa de crecimiento de las ventas de la industria y la participación que tiene este producto en el mercado, para luego clasificar si es un producto al que hay que invertir recursos para convertirlo en una fuente de ingresos importante para la empresa, o si se debe desinvertir en él (The Boston Consulting Group, 2019) (David, 2013):

Figura 6.2

Matric Boston Consulting Group de IOI

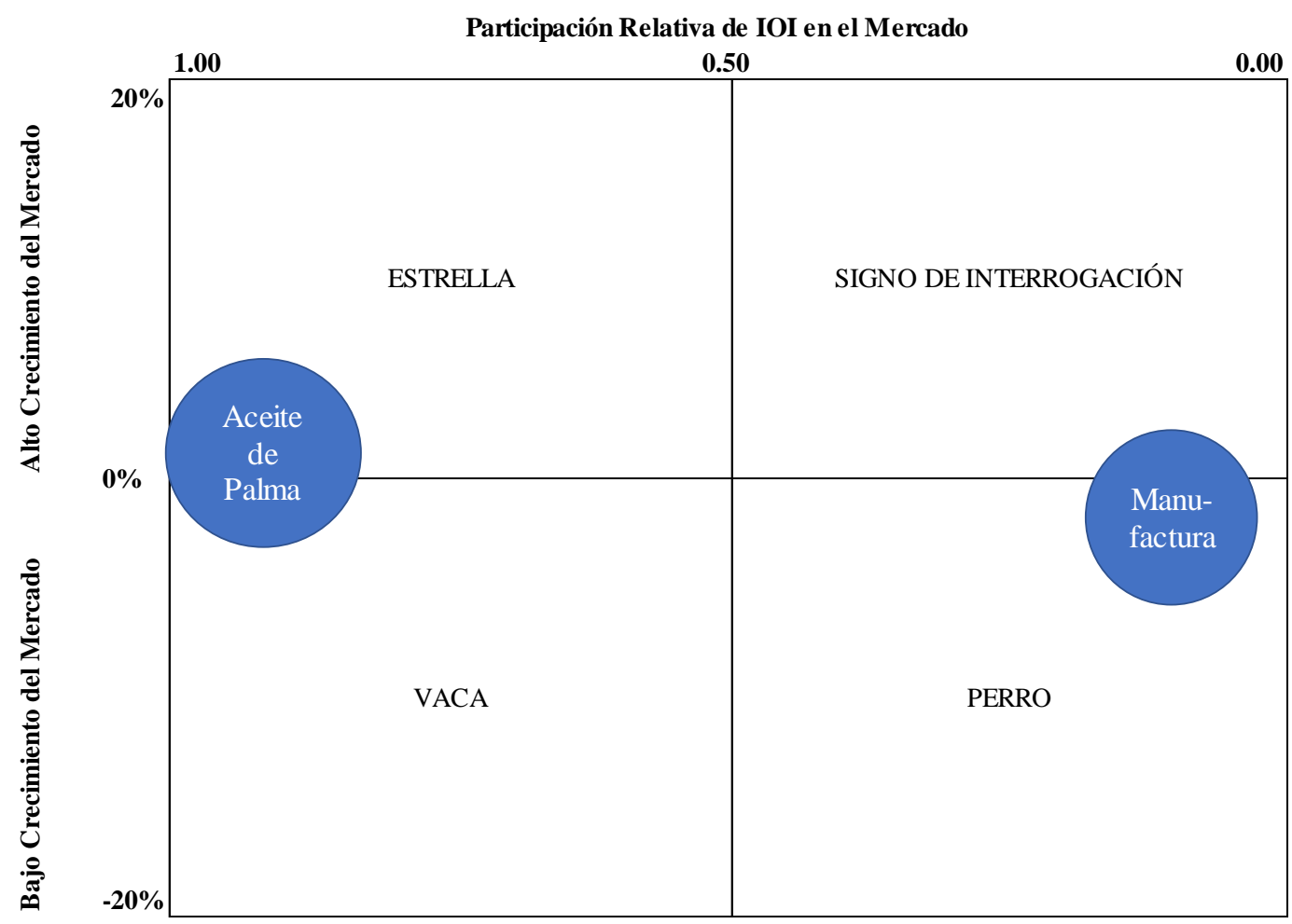

Nota: Datos complementarios en Anexo 1.

Elaboración Propia

Como resultado, y separando los productos que ofrece IOI en 2 segmentos, se obtuvo que el segmento de plantación y aceite de palma crudo, se encuentra en el cuadrante Estrella, lo que indica una alta participación relativa en el mercado, debido a 
que IOI es el líder del mercado (Ver Anexo 1, 2 y 3), tiene el puntaje más alto, y una industria que tiene presenta un crecimiento del 2.62\%, aunque esto lo pone en el cuadrante Estrella y signifique aplicar estrategias agresivas, está bastante cerca de convertirse en Vaca, que también supondrían estrategias de diversificación relacionada o integración horizontal (David, 2013).

Por otro lado, el segmento de manufactura que incluye oleo químicos dirigidos a industrias alimenticias, farmacéuticas y tecnológicas, se encuentra en el sector Perro, debido a una participación relativa débil de 0.16 , y un decremento de mercado de $-0.33 \%$ (Ver Anexo 1, 2 y 3)

- Matriz Interna - Externa

Esta Matriz toma en cuenta los resultados de las matrices de factores internos y externos, proponiendo estrategias según el puntaje y la ubicación relativa que obtuve la empresa y colocándola en 1 de los 9 sectores. Cada sector tiene asignada estrategias predeterminadas debido al rendimiento de la empresa, siguiéndose de la siguiente manera (McKinsey y Company, 2019):

- Sectores I, II y IV: Crecer y construir. Estrategias intensivas y de integración

- Sectores II, V Y VII: Retener y mantener. Estregias de penetración de mercado y desarrollo de producto.

- Sectores VI, VIII y IX: Cosechar y desinvertir. Estrategias defensivas. 
Figura 6.3

Matriz Interna-Externa de McKinsey y Company

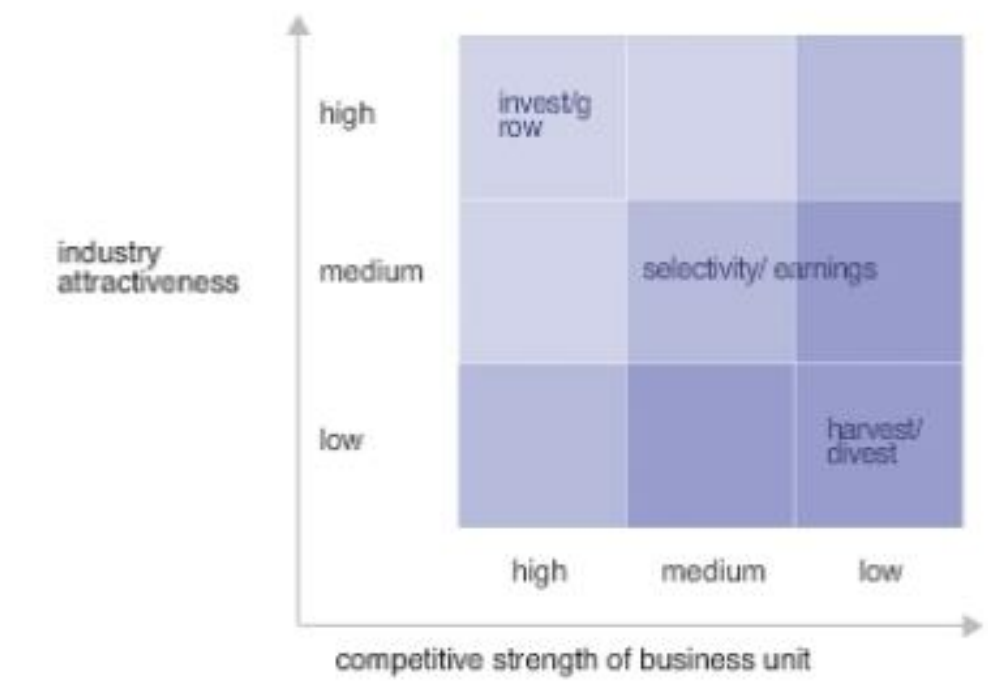

Fuente: McKinsey y Company (2019)

Como se observó anteriormente, la matriz EFE tuvo un resultado de 2.53, mientras que la matriz EFI tuvo uno de 2.56. Teniendo en cuenta que los resultados mínimos y máximos son 1 y 4, un resultado de 2.50 coloca a la empresa en un grado de respuesta medio, colocando a IOI en el sector V de la matriz IE, a lo que corresponden estrategias de penetración de mercados y desarrollo de productos para las unidades estratégicas de negocio que tiene la empresa.

- Matriz de la Gran Estrategia

Con esta matriz, el objetivo es evaluar las unidades estratégicas de negocio de la empresa y las coloca en una matriz según su posición competitiva y su grado de crecimiento. En esta, se identificaron las variables de calificación en base a la coyuntura actual, características que signifiquen una posición ventajosa dentro de la industria del aceite de palma e indicadores que midan la atractividad del mercado (Conservation International, 2019) o la alta dependencia que tenemos hacia este producto (National Geographic Magazine, 2019).

Cabe resaltar, que los criterios basados para este análisis son subjetivos ya que dependen de la industria y de quien lo elabora la elección de estos (David, 2013). 
Luego de elegir los criterios, se pesó y se calificó cada criterio con puntajes del 1 al 10, para luego multiplicar la suma de estos resultados por 10. Así, se obtiene un resultado del 1 al 100, medible y localizable en la matriz de la gran estrategia, donde se indica que el cuadrante en donde se encuentra la empresa es el IV, donde se recomienda una diversificación relacionada, integración horizontal y alianzas a través de Joint Venture (David, 2013)

\section{Figura 6.4}

\section{Matriz de la Gran Estrategia}

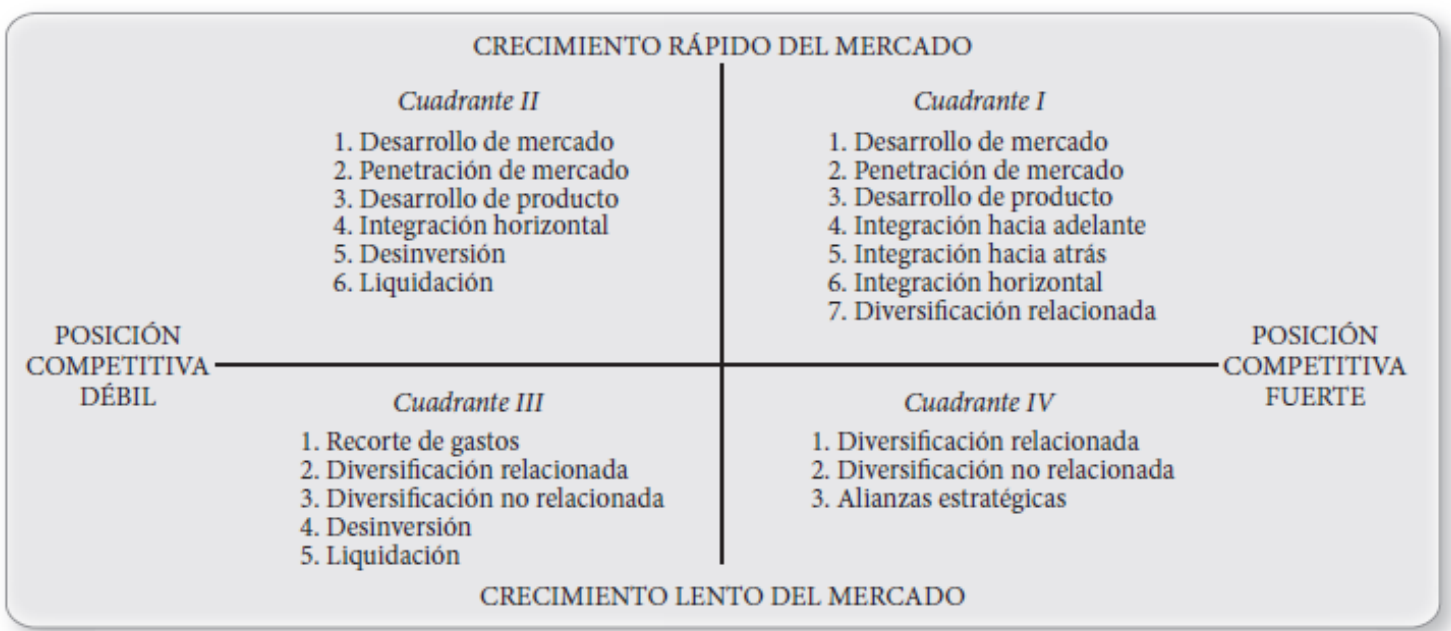

Fuente: Conceptos de Administración Estratégica (David, 2013) 
Tabla 6.10

Matrices de Posición Competitiva y Atractividad de Mercado

Posición Competitiva

\begin{tabular}{|c|c|c|c|c|c|}
\hline \multirow{2}{*}{ Factores } & \multirow{2}{*}{ Peso } & \multicolumn{2}{|c|}{ Palm Oil } & \multicolumn{2}{|c|}{ Manufacturing } \\
\hline & & Calificación & Ponderado & Calificación & Ponderado \\
\hline Capacidad de producción & $15 \%$ & 8 & 1.2 & 6 & 0.9 \\
\hline Calidad de producto & $15 \%$ & 7 & 1.05 & 7 & 1.05 \\
\hline Participación del mercado & $20 \%$ & 3 & 0.6 & 3 & 0.6 \\
\hline Fidelidad de los clientes & $15 \%$ & 8 & 1.2 & 6 & 0.9 \\
\hline Estructura de los costos & $15 \%$ & 6 & 0.9 & 6 & 0.9 \\
\hline \multirow[t]{3}{*}{ Reputación de la marca } & $20 \%$ & 7 & 1.4 & 4 & 0.8 \\
\hline & $100 \%$ & Total & 6.35 & Total & 5.15 \\
\hline & & & 63.50 & & 51.50 \\
\hline
\end{tabular}

\begin{tabular}{cccc} 
& \multicolumn{3}{c}{ Atractividad del mercado } \\
\cline { 2 - 4 } Factores & Peso & Calificación & Ponderado \\
\hline Market profitability & $15 \%$ & 8 & 1.2 \\
Variabilidad de la demanda & $15 \%$ & 7 & 1.05 \\
Poca competitividad & $15 \%$ & 3 & 0.45 \\
Tendencia de los precios & $20 \%$ & 8 & 1.6 \\
Diferenciación frente a otras industrias & $15 \%$ & 6 & 0.9 \\
Crecimiento del mercado & $20 \%$ & 3 & 0.6 \\
\cline { 2 - 4 } & $\mathbf{1 0 0 \%}$ & Total & $\mathbf{5 . 8 0}$ \\
\cline { 2 - 4 } & & & $\mathbf{5 8 . 0 0}$
\end{tabular}

Fuente: IOI Group (2019)

Nota: Elaboración Propia 


\section{- Matriz FODA}

En base a nuestro analisis interno y externo de la empresa, se elaboraron las estrategias combinadas en la matriz FODA, lo cual arrojó el siguiente resultado, tomando en cuenta las estrategias de crecimiento y desarrollo de David (2013). La matriz FODA es el resultado de la convergencia entre las matrices de evaluación externa e interna, en el cuál, tomando en cuenta los factores que afectan a la empresa, se proponen estrategias complementarias a una situación beneficiosa o que resuelvan un problema o desafío de la empresa. En este caso, se proponen 4 estrategias en base a lo resuelto:

1. Fortaleza y Oportunidad: Penetración y desarrollo de mercado ingresando al mercado sudamericano o adquiriendo plantaciones en esta región, y desarrollando productos en el segmento de combustibles.

2. Debilidad y Oportunidad: Desarrollo de Mercado. Vencer sus debilidades por ser muy cautelosos con sus estrategias y expandirse a nuevos mercados.

3. Fortalezas y Amenazas. Integración vertical hacia abajo. Para evitar posibles riesgos del mercado y de la industria, adquirir una empresa que este en un mercado directo con el consumidor final para solventar una posible crisis.

4. Debilidad y Amenazas: Desinversión. Proceder a desinvertir las unidades de negocio que menos beneficios aportan a la empresa y recuperar capital con esto. 


\section{Tabla 6.11}

\section{Matriz FODA de IOI}

\begin{tabular}{|c|c|c|c|}
\hline & & FORTALEZAS & DEBILIDADES \\
\hline & & 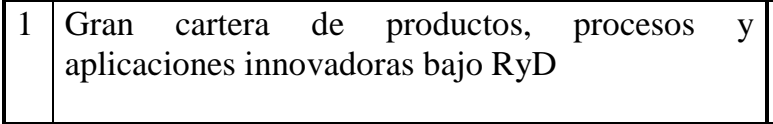 & \begin{tabular}{|l|l}
1 & $\begin{array}{l}\text { Bajos niveles de integración y retroalimentación entre } \\
\text { las operaciones por países. Cada una se maneja de } \\
\text { manera individual y poca integración de estrategias }\end{array}$ \\
\end{tabular} \\
\hline & & \begin{tabular}{|l|l|}
2 & Estado financiero en buen estado \\
\end{tabular} & \begin{tabular}{|l|l|}
2 & $\begin{array}{l}\text { Competencia posee más hectáreas plantadas. Mayor } \\
\text { materia prima }\end{array}$ \\
\end{tabular} \\
\hline & & \begin{tabular}{|l|l|}
3 & $\begin{array}{l}\text { "Customer centered approach" por parte de IOI } \\
\text { Group }\end{array}$ \\
\end{tabular} & Tasa de apalancamiento alta \\
\hline & & \begin{tabular}{|l|l|}
4 & Cadena de suministro renovada \\
\end{tabular} & \begin{tabular}{|l|l|}
4 & Reputación dañada por crisis de sostenibilidad
\end{tabular} \\
\hline & & \begin{tabular}{|l|l|}
5 & $\begin{array}{l}\text { Imagen y reputación de marca. Es reconocida a } \\
\text { pesar de sus fallas pasadas }\end{array}$
\end{tabular} & $5 \quad \begin{array}{l}\text { Conservadurismo y poca decisión de acción. Todas las } \\
\text { decisiones deben tener aprobación ejecutiva }\end{array}$ \\
\hline & OPORTUNIDADES & FO & DO \\
\hline 1 & Surgimiento de innovaciones y tecnologías nuevas. & & \\
\hline & $\begin{array}{l}\text { Posible crecimiento con nuevos productos de Loders } \\
\text { Crocklaan. }\end{array}$ & & \\
\hline 3 & Renovación hacia una marca eco amigable & Estrategia 1 (FO): Penetración y desarrollo de & Estrategia 2 (DO): Desarrollo de mercado \\
\hline 4 & \begin{tabular}{|l}
$\begin{array}{l}\text { Expansión en plantaciones en Sudamérica y nuevos } \\
\text { mercados objetivo. }\end{array}$ \\
\end{tabular} & & \\
\hline & $\begin{array}{l}\text { Diversificación de producto, ingresando al sector de energía } \\
\text { (biodiesel). }\end{array}$ & & \\
\hline
\end{tabular}


(continuación)

\begin{tabular}{|c|c|c|c|}
\hline & AMENAZAS & FA & DA \\
\hline 1 & Guerra comercial entre EE. UU y China tiene efectos globales. & \multirow{5}{*}{$\begin{array}{c}\text { Estrategia } 3 \text { (FA): Integración vertical hacia } \\
\text { abajo (clientes) }\end{array}$} & \multirow{5}{*}{ Estrategia 4 (DA): Desinversión } \\
\hline 2 & $\begin{array}{l}\text { Incumplimiento de normas sobre el medio ambiente, alta } \\
\text { exposición a los medios de comunicación y redes sociales }\end{array}$ & & \\
\hline 3 & Falta de adquisición y retención de talento humano & & \\
\hline 4 & $\begin{array}{l}\text { Políticas limitantes sobre plantaciones en el sudeste asiático en } \\
\text { plantaciones de palma. }\end{array}$ & & \\
\hline 5 & $\begin{array}{l}\text { Pestes y males que sufren las plantas de palma. Mal clima que } \\
\text { afecta producción de plantaciones. }\end{array}$ & & \\
\hline
\end{tabular}

Elaboración propia 
- Matriz de Decisión Estratégica

Esta matriz evalúa los resultados de todas las anteriores para decidir cuál será la estrategia que la empresa debe tomar para su situación actual según el análisis de sus actividades, escogiendo las estrategias que más hayan estado presente durante este ejercicio, resultando en que la estrategia con mayor sustento para realizarla es la estrategia de penetración de mercado y desarrollo de producto, tanto para las unidades de negocio más rentables, como plantaciones, y las divisiones de producto refinado, que a mayor inversión y estrategias agresivas pueden tener éxito y volverse más rentables.

Posteriormente, es necesario encontrar estrategias internacionales que se complementen con las estrategias corporativas recomendadas. Teniendo en cuenta esto, las estrategias internacionales y los modos de entrada a mercados internacionales expuestos por Bhandari (2013), se estudió la estrategia actual de IOI, que resulta ser una empresa enfocada en la innovación y por lo tanto, diferenciación. Al analizar el caso, se encuentra que entre las cualidades que posee IOI, esta el deseo de diferenciarse de su competencia mediante productos innovadores e intimidad con el cliente, esto fue impulsado justamente por la adquisición de Loders Croklaan y por la visión estratégica de sus ejecutivos, incluso se menciona que a estos se les daba una autonomía sustancial para la toma de decisiones en cada uno de sus mercados. Por ende, encontramos una empresa que tiene como estrategia principal, la diferenciación entre sus competidores y que, por lo menos, busca responder o actuar según las costumbres y gustos de cada país o región en la que compite, esto último se puede evaluar dentro de la matriz de Barlett y Ghoshal (1987) como diferenciación nacional, y se demuestra en la variación del producto Betapol según el país en el que se ofrecía, dando más promoción en China a la opción para infantes intolerantes a la lactosa y la libertad otorgada a sus ejecutivos regionales para administrar cada área. 
Tabla 6.12

Matriz de Decisión Estratégica

\begin{tabular}{|c|c|c|c|c|c|c|}
\hline \multirow{2}{*}{$\begin{array}{c}\text { Estrategias } \\
\text { Alternativas }\end{array}$} & \multirow{2}{*}{ Estrategias Específicas } & \multicolumn{4}{|c|}{ MATRICES } & \multirow[t]{2}{*}{ Total } \\
\hline & & FODA & IE & BCG & GE & \\
\hline $\begin{array}{l}\text { Penetración de } \\
\text { Mercado }\end{array}$ & $\begin{array}{l}\text { Buscar mayor participación de } \\
\text { mercado para los productos } \\
\text { existentes, que tienen lento } \\
\text { crecimiento pero "alta presencia" }\end{array}$ & $\mathrm{x}$ & $\mathrm{x}$ & $\mathrm{x}$ & & 3 \\
\hline $\begin{array}{l}\text { Desarrollo de } \\
\text { Producto }\end{array}$ & $\begin{array}{l}\text { Desarrollo de nuevos productos } \\
\text { innovadores a través de } \\
\text { investigación y RyD, beneficiándose } \\
\text { del input de Loders Croklaan. }\end{array}$ & $\mathrm{x}$ & $\mathrm{x}$ & $\mathrm{x}$ & & 3 \\
\hline $\begin{array}{l}\text { Desarrollo de } \\
\text { Mercado }\end{array}$ & $\begin{array}{l}\text { Encontrar nuevos mercados, } \\
\text { expandirse a ellos y aumentar la } \\
\text { rentabilidad de los productos que IOI } \\
\text { puede ofrecer }\end{array}$ & $\mathrm{x}$ & & $\mathrm{x}$ & & 2 \\
\hline $\begin{array}{l}\text { Integración } \\
\text { Vertical hacia } \\
\text { abajo (clientes) }\end{array}$ & $\begin{array}{l}\text { Debido a la crisis de China y EE.UU, } \\
\text { y posibles complicaciones ante } \\
\text { regulaciones estrictas sobre el aceite } \\
\text { de palma, integrarse verticalmente } \\
\text { con un consumidor para prevenir } \\
\text { cualquier caso de suspensión o crisis } \\
\text { económica, siempre habrá flujo de } \\
\text { ingresos }\end{array}$ & $\mathrm{x}$ & & $\mathrm{x}$ & & 2 \\
\hline Desinversión & $\begin{array}{l}\text { Venta de activos fijos, } \\
\text { reestructuración de gastos y manejo } \\
\text { de recursos para las unidades de } \\
\text { negocio menos exitosas }\end{array}$ & $\mathrm{x}$ & $\mathrm{x}$ & & & 2 \\
\hline $\begin{array}{l}\text { Diversificación } \\
\text { relacionada }\end{array}$ & $\begin{array}{l}\text { Diversificar su cartera de productos } \\
\text { hacia negocios relacionados, como } \\
\text { biodiesel }\end{array}$ & & & & $\mathrm{x}$ & 1 \\
\hline $\begin{array}{l}\text { Diversificación } \\
\text { no relacionada }\end{array}$ & $\begin{array}{l}\text { Diversificar los negocios del grupo a } \\
\text { unidades más rentables pero no } \\
\text { relacionadas }\end{array}$ & & & & $\mathrm{x}$ & 1 \\
\hline
\end{tabular}

Nota: Elaboración Propia 
Figura 6.5

Matriz de Barlett y Ghoshal

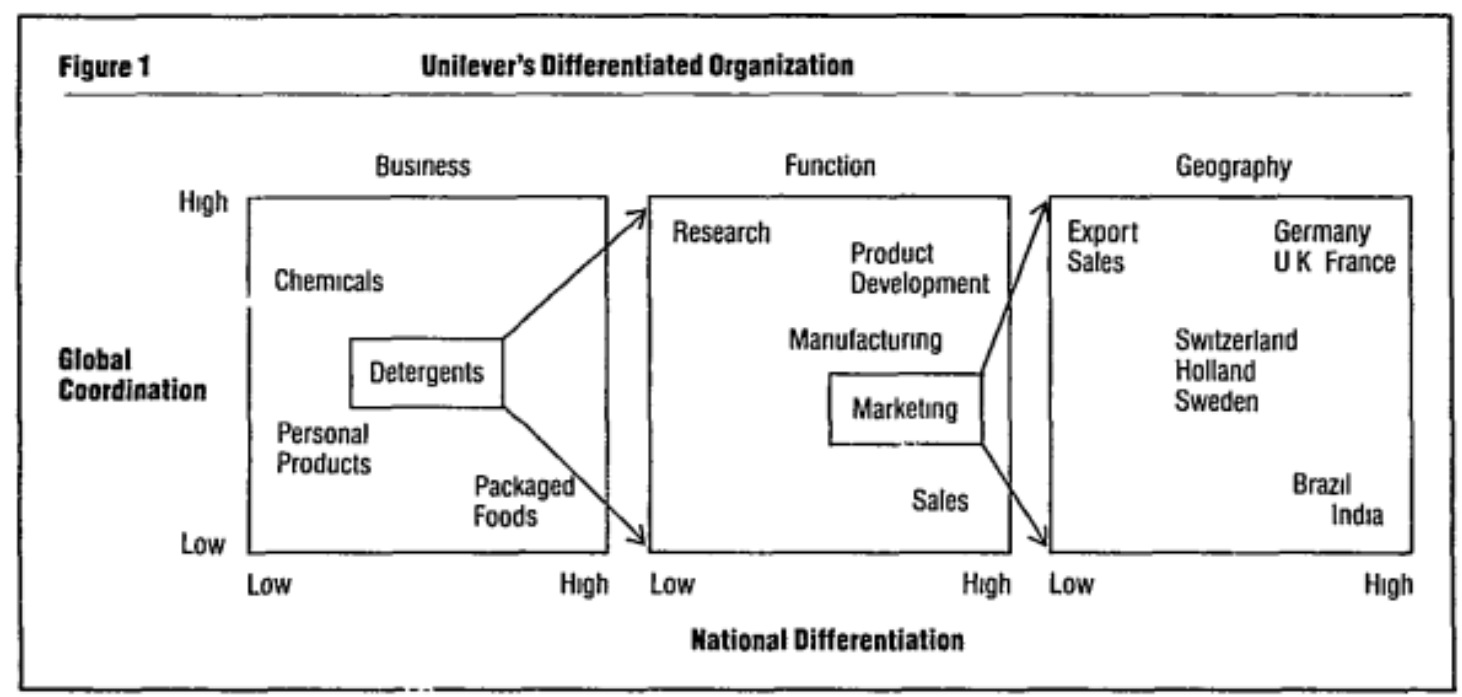

Fuente: Barlett y Ghoshal (1998)

Luego, se analizó el nivel de coordinación global que IOI tiene actualmente, en donde se muestra un nivel de descentralización importante. Como antes mencionado, los ejecutivos de cada país tienen total libertad para formular sus propias estrategias según convenga, provocando un desfase de coordinación al igual que diferencias debido a una estructura organizacional descentralizada por región. Como consecuencia, hay una gran adaptación local para cada región, pero hay pocos esfuerzos para implementar innovaciones a lo largo del grupo. Incluso, se puede afirmar que esto fue una de las causas de la crisis de sostenibilidad que la empresa enfrentó durante el 2015-2016, por falta de coordinación y comunicación, ya que irregularidades como las que enfrentó IOI en una sola plantación, afectaron a todo el grupo y a la marca internacionalmente. Por este motivo, se concluye que actualmente IOI es una empresa enfocada en la diferenciación de sus productos en una organización multidoméstica (Bhandari, 2013), con alto nivel de adaptabilidad local pero poca coordinación global.

En base a esto, se cree que la estrategia escogida es correcta para el ambito de la empresa, sin embargo también se tiene la convicción de que hay oportunidades de mejora que se pueden aplicar. En compañias de manufactura, es común encontrar que al otorgar demasiada independencia a cada subsidiaria, si bien facilitaba el manejo de la empresa 
reduciendo puntos de gestión a cargos de alto mando, se producen ineficiencias substanciales (Barlett y Ghoshal, 1998), "reinventando" estrategias u optimizando procesos que ya antes se manejaban dentro de la organización. Es indudable que hoy en día, el flujo de información y recursos de manera interdependiente entre las distintas subsidiarias, unidades de negocio o divisiones de una empresa, ya sea de forma doméstica o internacional, concluye en una resolución de problemas de manera más eficiente, así como la mejora de procesos internos. Se cree firmemente que IOI no ha alcanzado un punto óptimo con los recursos a su disposición, y esto se debe a la falta de interdependencia entre la misma empresa, esto se puede lograr mudando de estrategia de una multidoméstica a una trasnacional, en la que se identifiquen productos claves que necesiten una adaptación local y a aquellos que no la requieren, pero siempre con una colaboración integrada como parte de los valores de la empresa, en la que haya una disposición de colaboración y se alcancen mejores resultados, esto también producirá un ahorro en costos aunque este no es el principal objetivo de la estrategia.

\section{3 Área de Strategic Global Management}

Ahora bien, mucho del éxito de esta estrategia depende de la idiosincrasia y estructura de la empresa que la va a aplicar, sobre todo para una que espera cumplir objetivos internacionales a nivel global. El caso de IOI tiene un factor especial a considerar, es una empresa familiar, por lo tanto tiene características que difieren con otras empresas privadas.

En esta matriz FODA, se evaluaron los aspectos internos y externos que afectan a las empresas familiares, usando el estudio de Belausteguigoitia (2017) identificándose las siguientes posibles estrategias en base a la realidad de las empresas familiares:

- FO: Penetración y desarrollo de producto: Debido al beneficio otorgado por el gobierno, experiencia y apoyo de la comunidad, pueden impulsar la penetración de productos existentes y la creación de nuevos.

- DO: Con miras a minimizar las debilidades de la empresa y fomentar estrategias más agresivas de crecimiento, usar el apoyo del gobierno y los estados financieros con poco apalancamiento para sustentar un desarrollo de mercado, expandiéndose a nuevos países y ampliando su horizonte. 
- FA: Enfocados en reducir las amenazas y riesgos del entorno, surge la estrategia de diversificación relacionada para no verse afectados drásticamente en caso de la crisis de una industria.

- DA: Buscando alejar los posibles conflictos familiares por intereses y mantener un objetivo claro que exija a la empresa a cumplir objetivos retadores, una integración horizontal permitiría seguir creciendo a la compañía, entrando a nuevos sectores y mercados donde la empresa adquirida operaba.

Teniendo esto en cuenta, como opinión propia se considera que las empresas familiares tienen bastos beneficios al inicio de su formación, sin embargo su consolidación y estructura presenta varios desafíos provocados por disputas u esquemas poco organizados, usuales en organizaciones familiares, es necesario un auto control y profesionalización de la familia para llevar por buen camino su empresa. Por lo demás, no presentan ninguna otra ventaja o desventaja frente a organizaciones no familiares, el entorno resulta ser el mismo y las diferencias surgirán de la naturaleza de las relaciones internas de la empresa. 
Tabla 6.13

Matriz FODA de empresas familiares

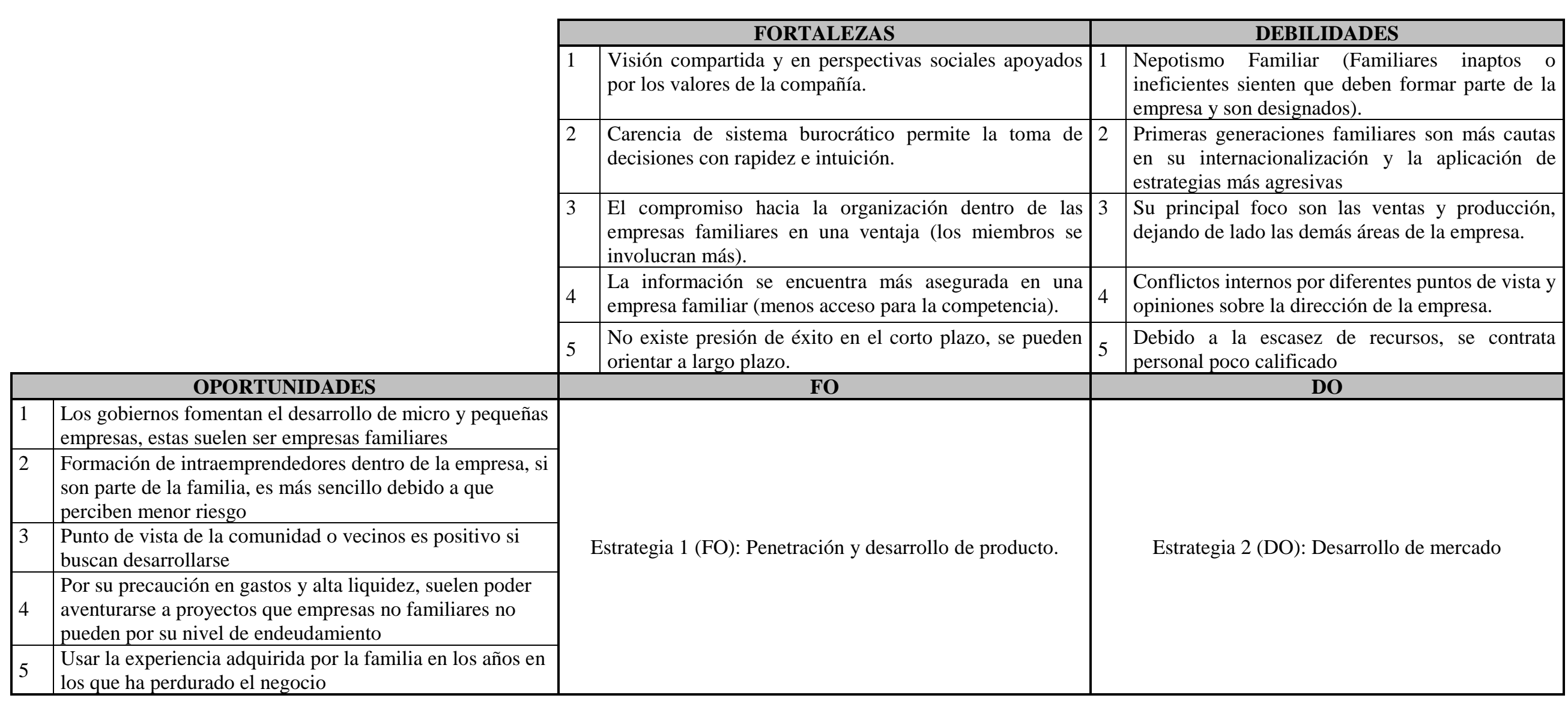

Continúa 
(continuación)

\begin{tabular}{|c|c|c|c|}
\hline & AMENAZAS & FA & DA \\
\hline 1 & $\begin{array}{l}\text { Conflictos externos pueden provocar inestabilidad en una empresa } \\
\text { familiar por distintas opiniones o puntos de vista }\end{array}$ & \multirow{5}{*}{$\begin{array}{c}\text { Estrategia } 3 \text { (FA): Diversificación } \\
\text { Relacionada }\end{array}$} & \multirow{5}{*}{ Estrategia 4 (DA): Integración Horizontal } \\
\hline 2 & $\begin{array}{l}\text { Disputas familiares por el control del poder o por la sucesión de la } \\
\text { empresa por intereses personales }\end{array}$ & & \\
\hline 3 & $\begin{array}{l}\text { Forzar a miembros de la familia a formar parte de la empresa puede } \\
\text { formar lideres insatisfechos y no aptos. }\end{array}$ & & \\
\hline 4 & $\begin{array}{l}\text { Empresas familiares tienden a relajarse debido a la falta de presión } \\
\text { y no alcanzan su pico }\end{array}$ & & \\
\hline 5 & $\begin{array}{l}\text { Un entorno no favorable no solo puede ser perjudicial para la } \\
\text { empresa, si no afectar directamente al sustento familiar, siendo } \\
\text { más fácil que la empresa se disuelva ante diversos riesgos }\end{array}$ & & \\
\hline
\end{tabular}

Fuente: Empresas familiares: dinámica, equilibrio y consolidación (2017). 
Considerando la información antes explicada, no existen razones para creer que una empresa familiar pueda tener algún beneficio o desventaja frente a organizaciones no familiares, ambas se enfrentan en un mismo contexto y mercado y será cuestión de sobreponer que empresa tiene personas mejores preparadas para enfrentar estos retos. Un plan de expansión en una empresa familiar, como lo ha planteado IOI, es perfectamente viable y a la vez tiene los mismos riesgos y dificultades que una empresa no familiar con los mismos objetivos.

Por otro lado, es de admirar el proceso con el cuál una organización pueda llegar a tener un grado de expansión de IOI, paso de ser una empresa local en Malasia a una “mini multi-nacional" como la nombró Lee. Por esto, tras analizar los factores y estrategias interna que permitieron que IOI creciera de tal manera, se ha identificado lo siguiente:

Lee adquirió Industrial Oxygen Incorporated tras haber tenido experiencia como supervisor de plantación. Lee, quien supervisaba todas las decisiones de la compañía en ese entonces, transmitió conocimientos y experiencia al crecimiento de la empresa. Empleó una estrategia de crecimiento orgánico y de adquisiciones cuando se trató de nuevas áreas en donde no había operado antes, heredando la experiencia y estructura de las compañías adquiridas y aportando los valores y las estrategias internas y externas de IOI. La época en la que la familia Lee inicia IOI (1980's) coincide con el apoyo gubernamental a la industria del aceite de palma, fomentando la inversión en proyectos de downstream que ayudó al crecimiento de IOI. Al mismo tiempo, surgió una demanda creciente hacia el aceite de palma crudo y sus derivados, por lo que tanto IOI como sus competidores recaudaron fondos para sus expansiones y se enfocaron en proyectos de downstream.

Otro factor importante es la estrategia para establecer una estructura interna, la cual se enfocó en otorgar autonomía a los ejecutivos de cada región, cuando Lee se dio cuenta de que no podía gestionar y participar personalmente de todas las decisiones de la empresa una vez que esta se expandió a varios paises. Esto permitió una adaptabilidad local de la empresa en cada región que permitió afianzarse en cada una de sus oficinas. Sin embargo, no todo fue siempre cuesta abajo para Lee e IOI, la empresa tuvo que enfrentar diversos desafíos en el trayecto para poder alcanzar sus objetivos. Uno de estos se presentó luego de la adquisición de Loders Croklaan, siendo el principal problema la estructura organizacional de la empresa recién adquirida. Si bien la adquisición significó 
un impacto positivo para el grupo, no se lograban mantener sinergias entre las subsidiarias regionales, mientras se tenía gran éxito en el mercado estadounidense insertando productos a gran escala, no se obtenía el mismo resultado para el mercado europeo. Esto se debió a que la estructura organizacional de Loders Croklaan fomentaba la adaptabilidad local, pero es esta descentralización la que no permitía compartir o trasladar conocimientos e innovaciones a través de las fronteras geográficas y transmitirlas a las operaciones en Europa. En palabras de Veitch: "Tomamos conocimiento de una región y las aplicamos en otra. Suena fácil de hacer, pero te sorprendería lo dificil que es hacer esto en práctica y lo mucho que se necesita en recursos y tiempo".

Algo es cierto, alcanzar este desarrollo debe ir acompañado de una ventaja a favor de la empresa, ya sea una comparativa frente a su competencia, o una competitiva, se quiere analizar la situación actual de la empresa en cuanto a sus elementos diferenciadores y si ha sido exitoso en sostener estas ventajas a lo largo del tiempo.

Según Porter (1985), las ventajas competitivas deben implicar un beneficio para la empresa frente a sus competidores, elementos diferenciadores que sean dificiles de replicar, y sobre todo deben ser sostenibles en el tiempo. Teniendo esto en cuenta, se puede responder a la siguiente pregunta: ¿Considera que IOI ha sido exitoso manteniendo sus ventajas competitivas? ¿Por qué sí o por qué no?

En primera instancia, queda claro por lo expuesto en párrafos anteriores, que IOI destaca por una estrategia competitiva genérica de diferenciación, esto implicó inversión en desarrollo e investigación, llegando incluso a la adquisición de Loders Croklaan, división de investigación de Unilever, permitiendo ofrecer productos de mayor calidad, además de tener una estrategia de cercanía con el consumidor. Estos elementos son difíciles de replicar dado que implica un cambio en la estructura de costos de una empresa que no ha estado enfocada anteriormente en esta estrategia, y forman el modelo de negocio actual de IOI.

En segunda instancia, se debe evaluar si esta estrategia ha sido sostenible en el tiempo para afirmar que es una ventaja competitiva (Porter, 1985). Considerando esto, se observa que IOI tuvo el esfuerzo de invertir en su estrategia mediante la adquisición de Loders Croklaan; sin embargo, no supo sacar provecho de esta división de investigación por la estructura interna de la empresa, optando por vender el $70 \%$ de IOI a Bunge. A 
simple vista, pareciera ser que perdió la oportunidad de encontrar mejores oportunidades que explotar ante su competencia por manejo estratégico ineficaz de esta división, que incluso en 5 años, como se realizó la transacción, Bunge tendrá el derecho de comprar el porcentaje restante de la empresa (Bunge, 2017). Este contrato se hizo para poder solventar las deudas de la empresa, y por lo dificultoso que resultó ser para IOI mantener niveles de inversión altos en innovación que requerían frutos para poder sustentar el flujo de capital, estos frutos debían ser productos estrella que al final no se desarrollaron o no se dieron en la cantidad necesaria.

Por último, teniendo estos dos factores en cuenta, se cree que la empresa no obtuvo éxito, debido a que no mantuvo su ventaja competitiva, transformandose por el momento en una ventaja comparativa debido a que ya cuenta con la estructura organizacional e ideologia del modelo de negocio.

Pensando en esto, surge la pregunta: ¿IOI, como empresa familiar, estaba mejor posicionada que una no familiar? Tal vez, era su destino, por su tipo de composición, no poder mantener su posición competitiva. Al mismo tiempo, mantener la división de investigación Loders Croklaan era una tarea ardua, pero se trataba de la división que abastecía directamente a sus clientes en Europa, quienes identificados como FastMoving Consumer Goods (FMCGs) Nestlé, Unilever y Procter and Gamble, hacen creer que la empresa no estuvo preparada para el desafío de enfrentar inversiones sostenibles al rubro de innovación, asumiendo la pérdida de abastecimiento de productos refinados y más procesados a estas multinacionales. Sin embargo, la pregunta recae en si la naturaleza de las empresas familiares permite que una empresa como IOI se vuelva innovadora y admirada a nivel mundial.

Para ser una empresa familiar que impulse la innovación como una estrategia competitiva, hay 2 características esenciales que permiten la evolución a este tipo de característica. En primer lugar, la voluntad de la empresa para innovar, y en segundo lugar, la disponibilidad de recursos para invertir en innovación, en donde las empresas familiares generalmente invierten menos que las empresas no familiares (De Massis, Di Minin, y Frattini, 2015). Sin embargo, el éxito o fracaso luego de implementar esta estrategia depende de otros factores como la correlación entre el deseo de invertir en innovación, los objetivos de la empresa familiar o la aversión al riesgo con la estrategia de innovación, es en este sentido que las empresas familiares, en su mayoría, no 
encuentran elementos en común, ya que sus estrategias suelen ser más orientadas a objetivos no económicos o más cautelosos, mientras que una estrategia enfocada en innovación y desarrollo de productos es una más agresiva (De Massis, Di Minin, y Frattini, 2015).

Por último, la propuesta que Julian Veitch realizó sobre una expansión ambiciosa que consistía en adquirir nuevas plantas, por una expansión greenfield o mediante fusiones y adquisiciones, en paises como Brasil e India, aludiendo que estos dos tipos de estrategias son necesarias para alcanzar los objetivos propuestos al 2025. Sin embargo, no se considera que este sea la mejor propuesta debido a la altísima tasa de apalancamiento que la empresa alcanzaría si es que se produce esta inversión. Además, como expuesto anteriormente, la empresa no cuenta con sinergias que pasen sus fronteras geográficas en la actualidad, con muy poca coordinación global entre cada oficina en el mundo, lo que provoca un lento crecimiento y un manejo ineficiente de los recursos invertidos. Es por esto que para el caso actual de la empresa, se sugiere utilizar una estrategia más conservadora, empezando por sugerir una de las opciones viables debido a su menor riesgo, la exportación de sus productos hacia nuevos países (Bhandari, 2013), esto puede ser complementado con un intermediario o bróker el cuál teniendo conocimiento del mercado local, pueda insertar de manera efectiva los productos de IOI hasta que adquiera know how o tenga clientes frecuentes, luego se podría evaluar en base a la demanda si se realiza una mayor inversión en los países en los que se tuvo éxito.

Otra opción viable es ingresar a nuevos mercados por medio de alianzas estratégicas, reduciendo la cantidad de recursos a invertir, compartiendo ventajas competitivas con los aliados locales en los nuevos mercados a los que se entrará, maximizando la eficiencia de los recursos y alcanzando nuevas oportunidades de venta para así cumplir con los objetivos planteados.

Por último, la empresa cuenta con una basta cantidad de patentes en desuso, siendo un activo desperdiciado del cual se puede sacar beneficio si se ofreciese un licenciamiento de estas patentes a partes interesadas, así la empresa recibiría regalías por las ventas de los licensee y sería un nuevo ingreso que requeriría muy poca, si no nula inversión. 


\section{4 Área Logística del Comercio Internacional}

Dentro del área logística, IOI ha implementado varios proyectos claves para la mejora de su cadena de suministro. En primer lugar, se planteó el objetivo de tener una cadena de suministro completamente trazable (IOI Group, 2018), desde la plantación hasta la entrega del producto al cliente, esto le permite a la empresa el monitoreo del traslado de su materia prima y entrega de productos finales, tener información en tiempo real del estado de estos, además junto con este proyecto se hizo el compromiso de un abastecimiento responsable; esto último forma parte de la segunda variable que interviene en el proceso de la cadena de suministro de la empresa, que es la sostenibilidad, mediante la aplicación de certificaciones que acrediten la reducción de huellas de carbono, de producción de aceite de palma sostenible acorde con las leyes nacionales de Malasia y los compromisos efectuados al RSPO (IOI Group, 2018). Por último, la cadena de suministro de IOI ha pasado por un proceso de integración para generar mayores márgenes y verse afectados por una menor volatilidad de los precios, esta integración se ha dado más en los mercados desarrollados, los que abastecen directamente a las FMCGs, cumpliendo con el suministro de productos de manera coordinada y a tiempo. Estos elementos incrementan el valor agregado de los productos de IOI y lo hacen más competitivo en un mercado fraccionado.

Como recomendación, se sugiere expandir estos proyectos a nivel global en mercados donde aún no estan aplicados en su totalidad, como mercados en desarrollo que tienen oportunidades de mejora, para lograr una cadena logística integrada global. En esto también se puede incluir alianzas con pequeños proveedores de servicios en Malasia e Indonesia que se encuentren cerca de las plantaciones y refinerías, debido a que en esos paises no se cuenta con una buena infraestructura de transporte y comunicaciones digitales (World Economic Forum, 2018). Invertir en un plan de responsabilidad social con empresas locales para mejorar estos aspectos impactaría directamente en el resultado del manejo logístico del inicio de la cadena de suministro de IOI, ya que en estos países surge la materia prima para alimentar los negocios de downstream y de aceite de palma crudo.

También, hay que tener en cuenta que el enfoque Just-In-Time (JIT) no se incluye en los conceptos de las prácticas de SCM en la industria del aceite de palma. Esto debido a que el nivel de infraestructura de Malasia e Indonesia, países donde IOI concentra sus 
plantaciones debido las condiciones climáticas favorables para el crecimiento de palma, y la alta volatilidad del mercado, que hace inadecuadas la práctica del JIT como forma de gestión de la cadena de suministro.

Como se mencionó anteriormente, la infraestructura de medios de transporte y de comunicación es importante para el éxito del JIT (Cheng, 2011), en ese sentido y según el World Economic Forum (2019), Malasia tiene un puntaje de 77.9 sobre 100 en la calificación de infraestructura al 2018, ubicándose así en el puesto 32 de 140 países, si bien esto es positivo, cuando individualizamos las características que complementan este puntaje, encontramos lo siguiente:

- En cuanto a conectividad de sus vías, Malasia ocupa el puesto 128 de 140 países, con un puntaje de 26.8 sobre 100 .

- En cuanto a su transporte por tren, Malasia ocupa el puesto 40 de 140 países, pero con un puntaje de 43.3 sobre 100 .

- En la categoría de conectividad a internet, necesaria para la transmisión de información en tiempo real, 8 de cada 100 personas tiene internet fijo, mientras que solo 4 de cada 100 posee fibra de alta velocidad, ubicándose en el puesto 77 de 140 países.

Estas características evidencian que los fundamentos para aplicar el principio de JIT en la cadena logistica de IOI es dificil de concretar por la realidad del país donde tienen el 90\% de sus plantaciones (IOI, 2019).

Por otro lado, según Christopher (2011), las prácticas JIT son difíciles de replicar en industrias con alta volatilidad debido al riesgo que implica para las empresas demandas inestables que impliquen un quiebre en stock o sobre costos de almacenamiento de producto no terminado, y siendo la industria de aceite de palma, altamente volátil (Haron y Ayojimi, 2015). Al mismo tiempo, tener sus plantaciones concentradas en un solo lugar, aunque permita alcanzar economías de escala con mayor facilidad, hace que las distancias de abastecimiento sean más largas para diferentes países, viendose afectada la industria en caso haya un cambio en la demanda repentino.

Debido a esto, corresponde evaluar el papel de Lee haciéndose las siguientes preguntas: ¿Fue por medio de Lee que se canalizaron todas las operaciones de downstream y upstream? ¿Fue Lee el enlace esencial que supervisó todos los negocios? 
Se considera que después de la adquisición de Loders Croklaan, fomentando el crecimiento de las operaciones de downstream, IOI se expandió de tal manera que era imposible supervisar todas las acciones correspondientes a diversos eventos, así como supervisar personalmente los negocios como lo hacía anteriormente. Para poder administrar de forma correcta al grupo, Lee les dio libertad a sus ejecutivos para administrar los negocios según su ubicación, permitiendo un mejor manejo logístico por un flujo de información más organizado y no centralizado en una sola persona. Además, según Chopra y Meindl (Chopra y Meindl, 2013) el efecto látigo tendría un efecto negativo si una persona llevará las coordinaciones de todas las operaciones entre negocios, un mínimo desliz resultaría en impactos negativos tanto para el negocio downstream como upstream, es por eso que se requiere una transmisión de la información de forma integrada entre divisiones de negocio y en tiempo real, en el que el flujo de información se transmita sin ser interrumpido para evitar complicaciones en la gestión de los recursos y procesos.

\section{5 Área Financiamiento Internacional}

Con la finalidad de evaluar a la empresa en todos los aspectos, se procedió al análisis de los estados financieros de IOI, teniendo las siguientes observaciones:

- Las reservas legales de la empresa forman parte excesiva del patrimonio de IOI, llegando a representar un $86 \%$ del total de patrimonio al 2017. Esto podría servir para solventar los pasivos corrientes de la empresa hasta estabilizarlos o tener un apalancamiento más saludable.

- La empresa adquirió Propiedad, Planta y Equipo, recurriendo a deudas corrientes en plazos próximos, considero que esto puede ser riesgoso para la empresa considerando las últimas crisis sufridas. Esto también se evidencia en la ratio de deuda neta sobre patrimonio, que aunque se ha reducido, sigue teniendo altos niveles de apalancamiento.

- La empresa recientemente ha vendido acciones, esto se deduce por el ingreso de capital de acciones y la disminución de los dividendos por acción. Al mismo tiempo, los activos por acción han aumentado. Esto debe significar que este ingreso adicional también fue usado para la adquisición de PPE que tuvo la 
empresa en el 2016. Si bien esto es una estrategia agresiva para expandirse, hace menos atractivo adquirir acciones de la empresa, más aún cuando estas no estan pagando grandes dividendos hace 5 años. Esto también puede significar una reducción del market capitalization de la empresa.

- Se realizó la valorización de la empresa en base a 2 métodos. El primero, de Valor Presente Ajustado, en el que se simula que la empresa solo se financiará con fondos propios; por otro lado, el método Weighted Average Cost of Capital (WACC) tasa el valor de la empresa según recursos propios como por endeudamiento (Ross, Westerfield, y Jaffe, 2012). Acorde a esto, suponemos que este último método calza mejor para el ejercicio con IOI.

Tabla 6.14

Valorización IOI por método VPA

\begin{tabular}{lr} 
K0 & $4.30 \%$ \\
VAN 1 & $\mathrm{S} / 8,055.25$ \\
VAN2 & $\mathrm{S} / 62.01$ \\
\hline VE (VPA) & $\mathbf{S} / \mathbf{8 , 1 1 7 . 2 6}$ \\
\hline
\end{tabular}

Nota: Elaboración propia.

Tabla 6.15

Valorización IOI por método WACC

\begin{tabular}{lr} 
WACC & $5.79 \%$ \\
\hline VE (WACC) & $\mathbf{7 , 5 9 2 . 3 6}$ \\
\hline
\end{tabular}

Nota: Elaboración propia.

Teniendo en cuenta el resultado de estas dos valoraciones, la empresa se encuentra en buen estado y tiene valorización positiva (Ver Anexo 4). Luego, también cabe la duda si es que sería adecuado aceptar acciones de IOI como medio de pago, en mi opinión, si 
tuviera que aceptar acciones de IOI a modo de pago, tendría que evaluar el riesgo que estaría dispuesto a aceptar, debido a que durante los últimos 5 años, los ingresos básicos por acción han disminuido un $15 \%$ promedio anual, mientras que los dividendos brutos por acción disminuyeron en $9 \%$ promedio anual. También es probable que una empresa con los niveles de apalancamiento que tiene IOI y que siga invirtiendo y adquiriendo activos vaya a estar desbalanceada en un futuro.

Por otro lado, es probable que los precios de las acciones hayan bajado a un nivel en el no puedan seguir disminuyendo su valor mucho más, si bien es riesgoso, podría considerarse la opción tomando en cuenta el precio de las acciones. Sin embargo, IOI no parece tener una estrategia clara de inversión y de revalorización de la empresa, para atraer capital externo. Esto sumado a que las empresas familiares no suelen presionarse por elementos externos tanto como las privadas, y priorizan el bienestar de la familia y el control que poseen (Belausteguigoitia, 2017), a IOI no tenga como prioridad hacer su empresa más atractiva para sus accionistas. Por este motivo, no aceptaría un pago en acciones por parte de IOI.

Por otra parte, se realizaron las proyecciones financieras de la empresa al año 2025, con miras de poder observar si la meta propuesta era alcanzable (Ver Anexo 5). El resultado fue negativo, dado que Veitch trazó la meta de duplicar ingresos y triplicar utilidades, esto no se dio en ninguno de los 2 indicadores, aunque de igual manera la empresa tuvo un cambio positivo en la relación deuda y patrimonio, así como crecimiento en los objetivos propuestos.

Para la elaboración de esta proyección, se consideraron los siguientes supuestos:

Tabla 6.16

Supuestos para la proyección financiera de IOI

\begin{tabular}{lcccccccc} 
SUPUESTOS & $\mathbf{2 0 1 8}$ & $\mathbf{2 0 1 9}$ & $\mathbf{2 0 2 0}$ & $\mathbf{2 0 2 1}$ & $\mathbf{2 0 2 2}$ & $\mathbf{2 0 2 3}$ & $\mathbf{2 0 2 4}$ & $\mathbf{2 0 2 5}$ \\
\cline { 2 - 8 } Tasa de crecimiento (g) & $1.11 \%$ & $3.10 \%$ & $6.10 \%$ & $7.41 \%$ & $4.40 \%$ & $5.24 \%$ & $5.78 \%$ & $5.70 \%$ \\
Supuesto Adquisición AFN & $2.5 \%$ & $2.5 \%$ & $2.5 \%$ & $5 \%$ & $5 \%$ & $5 \%$ & $10 \%$ & $10 \%$ \\
Cambio Pagos Current Liabilities & $11 \%$ & $5 \%$ & $5 \%$ & $5 \%$ & $3 \%$ & $3 \%$ & $3 \%$ & $3 \%$ \\
Aumento del Share Capital & $4.05 \%$ & $4.86 \%$ & $5.80 \%$ & $6.97 \%$ & $8.41 \%$ & $6.01 \%$ & $6.40 \%$ & $6.72 \%$ \\
Pago con Reservas & 0 & 0 & $15 \%$ & 0 & 0 & $15 \%$ & 0 & 0 \\
Net Foreign Current Loss & -250 & -250 & -250 & -250 & -250 & -250 & -250 & -250 \\
Net Intereset Expenses & -185 & -185 & -185 & -185 & -185 & -185 & -185 & -185
\end{tabular}


- La tasa de crecimiento corresponde a la extracción del crecimiento anual ponderado de los últimos 5 años.

- Supuesto de adquisición de Activo fijo neto, el cuál crece de manera gradual ya que se considera una desinversión en el segmento de manufactura, al mismo tiempo de una estrategia expansiva para el segmento de aceite de palma crudo y plantaciones.

- Inyección progresiva de capital de acciones

- Debido a los altos niveles de reservas legales, se propone pagos a los pasivos corrientes en el 2020 y el 2023 , del $15 \%$ del total de reservas.

- El promedio del 2012 al 2017 de pérdida por tipo de cambio fue de 240 millones de MYR. Por lo que se estableció un promedio de 250.

- El promedio por gastos de interes netos fue de 185, por lo que se estableció esta pérdida de manera fija

Por último, se cree que para expandir sus horizontes a nuevos mercados no emergentes, es necesario revisar los siguientes indicadores:

- La condición de la industria y de la competencia en el pais objetivo, esto puede servir para aprender de la estructura de las empresas ya establecidas y obtener recomendaciones.

- Fortaleza financiera interna, reflejada a través del grado de apalancamiento, activos disponibles, sobre todo el activo corriente.

- Regulaciones financieras del país objetivo, como el impuesto a la renta o de entrada al pais. 


\section{CONCLUSIONES}

Habiendo culminado el análisis de este caso, resumimos los hallazgos y resultados encontrados:

1. Las crisis de sostenibilidad y de comunicación que enfrentó IOI ha mermado sus resultados y afectado la estabilidad financiera de la empresa. En el primer caso, la empresa se ha vuelto menos atractiva tras una disminución de los dividendos por acción, esto debido a una venta de acciones para solventar parte de la deuda que la empresa tenía en el 2016 y posteriormente para la adquisición de activos. Esto sumado al bajo rendimiento en el año 2015 debido a condiciones climáticas adversas que afectaron a las plantaciones de IOI y el poco dinamismo que presentó la industria ese año, terminaron dañando el estado de la empresa. Recientemente, se han visto obligados a vender su división de Investigacion y Desarrollo, Loders Croklaan, debido a bajos rendimiento y alto nivel de deuda, afectando así su ventaja competitiva como lo era su diferenciación por sobre las demás empresas protagonistas en su industria.

En segundo lugar, la crisis de comunicación afectó a la imagen de la empresa, haciéndola ver poco responsable y consciente con la realidad actual del medio ambiente. Como consecuencia, grandes clientes dejaron de abastecerse con sus productos durante el 2015 y 2016, acrecentando la crisis financiera que tenía IOI y obligándose a formar una estrategia de comunicación reactiva, que además tuvo una lenta respuesta ante las acusaciones por Aidenvironment, provocando su suspensión de la certificación de la RSPO.

2. IOI ha mostrado poco compromiso en los últimos 5 años con las estrategias establecidas, que a pesar de afirmar que es una empresa enfocada e la diferenciación de sus productos y enfocados a una atención al cliente superior, la empresa ha hecho recortes en las áreas más importantes y que daban mayor valor agregado a sus productos, como lo fue la venta de Loders Croklaan. Además, el conservadurismo a 
llevado a la empresa a tener grandes cantidades de reservas legales que no han sido usadas de manera eficiente.

3. Como antes mencionado, una de las conclusiones encontradas en este caso, es el uso ineficiente de los activos de la empresa, demostrado principalmente con el uso de las patentes que adquirió IOI desde el 2002 hasta el 2018, cuando seguía siendo propietaria de Loders Croklaan. IOI no pudo poner en balance la cantidad de recursos a invertir en la investigación de nuevos productos los cuales patento, y la disposición de los recursos para el desarrollo de estas patentes que llegaron a ser más de 200. Ciertamente la empresa no invirtió en todos los proyectos ideados, pero tampoco aprovechó al máximo estos activos.

4. IOI cuenta con una cadena de suministro integrada, esto le ha permitido eficiencias en una industria altamente volátil. Teniendo esto en cuenta, aún hay espacio de mejora en el alcance de los beneficios de esta cadena, esto debido a que las plantaciones de la empresa se encuentran en Malasia e Indonesia, países donde la infraestructura vial y digital no está totalmente desarrollada o no es de fácil acceso según el World Economic Forum. 


\section{RECOMENDACIONES}

Finalmente, se recomiendan los siguientes puntos:

1 Analizar un posible ingreso a Holanda y Vietnam, ya que estos paises se muestran atractivos para el ingreso de productos, o en su defecto, penetración de productos a base de aceite de palma.

2 IOI debería de reconsiderar su estrategia de comunicación para dirigirse a todos los stakeholders interesados en las operaciones de la empresa, no solo los que le benefician directamente, si no incluyendo también a ONG's, medios de comunicación y público en general, para emitir un mejor mensaje, remediar su reputación y volverla una fortaleza. Para este caso, se recomienda una estrategia de Relaciones Públicas, en las que a través de eventos, medios y presencia en público, se mejore la percepción de la empresa y beneficiar al público objetivo y a la empresa misma.

3 Se recomienda aplicar estrategias diferentes para cada uno de sus segmentos. En el caso de los productos sin refinar y exportaciones directas de palma, se observó que la empresa era líder de la industria, por lo que debería aplicar una estrategia de penetración de mercado y desarrollo de mercado, buscando captar más clientes y formar una base sólida antes de que este segmento deje de crecer en el mercado. Por otro lado, su segmento de productos refinados y de manufactura, a pesar de ser los productos a los que más se invierten, estos no logran tener resultados, es por esto que se proponen estrategias de penetración de mercado, debido a que cuando se realizó el estudio de matriz BCG, el segmento estaba clasificado como perro pero muy cerca de ser un signo de interrogación, creo que una estrategia basada en inversión y en captar sinergias entre su organización para lograr un crecimiento eficiente es esencial, parece ser que la empresa creció aceleradamente sin tener en cuenta aspectos organizacionales internos.

4 La empresa no debería seguir la propuesta de Veitch sobre la expansión de IOI mediante gastos intensivos de capital y endeudamiento, más aún cuando los mercados objetivos no fueron mercados que arrojaron el mejor resultado en el 
ranking de factores. La empresa ha invertido durante años en su expansión, es momento de consolidar sus operaciones hasta que vuelva a tener solidez en el mercado.

5 Durante el tiempo que IOI manejaba Loders Croklaan, la empresa adquirió gran cantidad de patentes que están en desuso, podrían internacionalizarse por medio de licencias, así ese activo no está empozado y generaría regalías.

6 La cadena de suministro ya se integró en los paises desarrollados, sin embargo gran parte de las operaciones de la empresa se encuentran en paises de desarrollo que cuentan con menos recursos y menos medios para ser competitivos, entre estos se encuentra la infraestructura, comunicaciones, entorno empresarial, etc. Como estrategia deberían integrar esta parte del mundo para tener una cadena logística eficiente.

7 Financieramente, la empresa debe buscar el bienestar económico mediante inversiones más inteligentes y procediendo a adquisición de propiedad de una manera más sostenible. El valor de sus acciones puede estar en descenso por los pocos dividendos que generan hoy en día a comparación de hace 5 años. 


\section{REFERENCIAS}

Aidenvironment. (2019). Roundtable on Sustainable Palm Oil. Recuperado de https://ap8.salesforce.com/sfc/p/\#90000000YoJi/a/90000000PXID/64LXFHsVt OINBbxi1qAVupBcwoOvZDUXp2z.xlA1SOQ

Astra Agro Lestari. (2019). Investor Relation. Recuperado de http://www.astraagro.co.id/en/annual-report/

Banco Mundial. (2019). World Bank. Recuperado de https://databank.worldbank.org/source/world-development-indicators

Bankia Estudios. (2019). Bankia Estudios. Recuperado de https://www.bankiaestudios.com/estudios/es/publicaciones/monitor-demercados-emergentes-13-marzo-2019.html

Barlett, C. A., y Ghoshal, S. (1998). Managing across Borders: New Organizational Responses. Sloan Management Review, 43-53.

Belausteguigoitia, I. (2017). Empresas familiares: dinámica, equilibrio y consolidación (4 ed.). Ciudad de México: Mc Graw Hill.

Bhandari, A. (2013). Strategic Management: A Conceptual Framework (1 ed.). Mc Graw Hill Education.

Bloomberg. (2019). Treasury Yields. Recuperado de https://www.bloomberg.com/markets/rates-bonds/government-bonds/us

Bunge. (2019). Bunge to Acquire 70\% Ownership Interest in IOI Loders Croklaan. Recuperado de https://www.bunge.com/news/bunge-acquire-70-ownershipinterest-ioi-loders-croklaan-create-leading-solutions-provider-b2b

Cheng, L.-C. (2011). Logistics Strategies to Facilitate Long-Distance Just-in-Time Supply Chain. (D. p. Li, Ed.) Shanghai: Intech.

Chopra, S., y Meindl, P. (2013). Administración de la Cadena de Suministro: Estrategia, planeación y operación (5 ed.). Naucalpan: Pearson. 
Christopher, M. (2011). Logistics y Supply Chain Management (4 ed.). Edinburgo, Reino Unido: Pearson.

Conservation International. (2019). Conservation International. Recuperado de https://www.conservation.org/blog/what-you-need-to-know-about-palm-oil-in5-charts

Damodaran, A. (2019). Betas by Sector. Recuperado de http://pages.stern.nyu.edu/ adamodar/New_Home_Page/datafile/Betas.html

David, F. R. (2013). Conceptos de Administración Estratégica (14 ed.). México: Pearson.

De Massis, A., Di Minin, A., y Frattini, F. (2015). Family-Driven Innovation: Resolving the Paradox in Family Firms. California Management Review, 5-19.

Felda Globe. (2019). Investor Relations. Recuperado de http://www.fgvholdings.com/investors/

Golden Agri-Resources Limited. (2019). Golden Agri-Resources Limited. Recuperado de https:/goldenagri.com.sg/investors/financial-information/annual-reports/

Haron, R., y Ayojimi, S. (2015). Malaysian Crude Palm Oil Market Volatility: A GARCH Approach. International Journal of Economics and Management, 103-120.

Shapiro, B.P., Bonoma, T.V. (2019). How to Segment Industrial Markets. Harvard Business Review. Recuperado de https://hbr.org/1984/05/how-to-segmentindustrial-markets

Hernández Sampieri, R., Fernández Collado, C., y Baptista Lucio, P. (2014). Metodología de la Investigación (6 ed.). Ciudad de México: Mc Graw Hill Education.

Indofood. (2019). Indofood. Recuperado de https://www.indofood.com/investorrelation/annual-report

IOI Group. (2018). Annual Report 2018: Fortifying Streghts . Recuperado de IOI Group: https://www.ioigroup.com/Content/IR/PDF/AR/2018_AR.pdf

IOI Group. (2018). IOI Group Sustainable Palm Oil Policy. Recuperado de https://www.ioigroup.com/Content/S/PDF/Sustainable\%20Palm\%20Oil\%20Poli cy.pdf 
IOI Group. (2019). Investor Relations. Recuperado de IOI Group: https://www.ioigroup.com/Content/IR/IR_Reports

Keller, K. L. (2013). Strategic Brand Management: Building, Measuring, and Managing Brand Equity (4 ed.). Upper Saddle River: Pearson.

Kotler, P., y Keller, K. L. (2012). Dirección de Marketing (14 ed.). México: Pearson.

Kuala Lumpur Kepong Berhad. (2019). Annual Report. Recuperado de https://www.klk.com.my/investor-media/financial-information/annual-reports/

McKinsey and Company. (2019). McKinsey and Company. Recuperado de https://www.mckinsey.com/business-functions/strategy-and-corporatefinance/our-insights/enduring-ideas-the-ge-and-mckinsey-nine-box-matrix

Ming, K.K., Chandramohan, D. (2002). Malaysian Palm Oil Industry at Crossroads and its Future Direction. Oil Palm Industry Economic Journal, 10-15.

National Geographic Magazine. (2019). National Geographic. Recuperado de https://www.nationalgeographic.com/magazine/2018/12/palm-oil-productsborneo-africa-environment-impact/

Nestlé. (2019). Nestlé. Recuperado de https://www.nestle.com/assetlibrary/documents/library/documents/suppliers/nestle-responsible-sourcingstandard-english.pdf

Organización de las Naciones Unidas para la Alimentación y la Agricultura. (2019). Food and Agriculture Organization. Recuperado de http://www.fao.org/faostat/es/\#data/QC

Porter, M. (1985). Competitive Advantage: Creating and Sustaining Superior Performance (1 ed.). Nueva York: The Free Pass.

Ross, S., Westerfield, R., y Jaffe, J. (2012). Finanzas Corporativas (9 ed.). Ciudad de México: Mc Graw Hill.

Roundtable on Sustainable Palm Oil. (2019). Roundtable on Sustainable Palm Oil. Recuperado de https://askrspo.force.com/Complaint/s/case/50090000028Erz8AAC/detail 
SyP 500. (2019). SyP Dow Jones Indices. Recuperado de https://us.spindices.com/indices/equity/sp-500

Shapiro, B. P., y Bonoma, T. V. (2019). How to Segment Industrial Markets. Harvard Business Review. Recuperado de https://hbr.org/1984/05/how-to-segmentindustrial-markets

The Boston Consulting Group. (2019). The Experience Curve - Reviewed. Recuperado de https://www.bcg.com/documents/file13904.pdf

$\begin{array}{llll}\text { TradeMap. } & \text { (2019). } & \text { TradeMap. }\end{array}$ https://www.trademap.org/Country_SelProduct_TS.aspx?nvpm=1\%7c\%7c\%7c \%7c\%7c151110\%7c\%7c\%7c6\%7c1\%7c1\%7c1\%7c2\%7c1\%7c2\%7c1\%7c

Unilever. (2019). Recuperado de https://www.unilever.com/news/pressreleases/2016/Unilever-reacts-to-palm-oil-suppliers-suspension-fromRSPO.html

Wilmar International. (2019). Annual Reports. Recuperado de https://ir-media.wilmarinternational.com/annual-reports/

World Economic Forum. (2019). Global Competitiveness Report 2018. Recuperaedo de http://reports.weforum.org/global-competitiveness-report-2018/competitivenessrankings/ 


\section{BIBLIOGRAFÍA}

Cateora, P., Gilly, M., y Graham, J. (2014). Marketing internacional. Ciudad de México: Mc Graw Hill.

Czinkota, M., y Ronkainen, I. (2013). Marketing internacional. Cengage Learning Editores.

Dutch Centre for the Promotion of Imports from Developing Countries - CBI and Swiss Import Promotion Programme - SI'P. (2010). Export manual: Exporting to Europe, an introduction. Rotterdam: CBI and SIPPO.

Guerra, H. (2014). Marketing internacional: Un enfoque práctico; teoría, casos y talleres. Bogotá: ALFAOMEGA.

Hedin, H., Hirvensalo, I., y Vaarnas, M. (2011). Handbook of market intelligence: understand, compete and grow in global markets. New York: Wiley.

Hernández Sampieri, R., Fernández Collado, C., y Baptista Lucio, P. (2014). Metodología de la Investigación. Ciudad de México: Mc Graw Hill Education.

Hollensen, S., y Arteaga, O. (2010). Estrategias de marketing internacional. Harlow: Prentice Hall Pearson.

Lambin, J. (2003). Marketing estratégico. Madrid: ESIC.

Mediano, S., y Beristain, J. (2015). Marketing práctico para pequeños negocios. Madrid: Pirámide.

Munuera, A., y Rodríguez, E. (2016). Estrategias de marketing: Un enfoque basado en el proceso de dirección. Madrid: ESIC.

Tang, M. (2015). La inteligencia de mercado en las empresas exportadoras e importadoras peruanas. Ingeniería Industrial(33), 71-97. 
World Economic Forum (2019). Global Competitiveness Report 2018. Recuperado de WEF: http://reports.weforum.org/global-competitiveness-report2018/competitiveness-rankings/ 
ANEXOS 


\section{Anexo 1 Ingresos por segmento de principales competidores en la industria de Aceite de Palma}

\begin{tabular}{|c|c|c|c|c|c|c|c|c|c|c|}
\hline & \multicolumn{2}{|c|}{2013} & \multicolumn{2}{|c|}{2014} & \multicolumn{2}{|c|}{2015} & \multicolumn{2}{|c|}{2016} & \multicolumn{2}{|c|}{2017} \\
\hline & $\begin{array}{c}\text { Plantaciones } \\
\text { y aceite de } \\
\text { palma crudo }\end{array}$ & $\begin{array}{c}\text { Oleo } \\
\text { químicos, } \\
\text { refinados y } \\
\text { derivados }\end{array}$ & $\begin{array}{l}\text { Plantaciones } \\
\text { y aceite de } \\
\text { palma crudo }\end{array}$ & $\begin{array}{c}\text { Oleo } \\
\text { químicos, } \\
\text { refinados y } \\
\text { derivados }\end{array}$ & $\begin{array}{l}\text { Plantaciones } \\
\text { y aceite de } \\
\text { palma crudo }\end{array}$ & $\begin{array}{c}\text { Oleo } \\
\text { químicos, } \\
\text { refinados y } \\
\text { derivados }\end{array}$ & $\begin{array}{l}\text { Plantaciones } \\
\text { y aceite de } \\
\text { palma crudo }\end{array}$ & $\begin{array}{c}\text { Oleo } \\
\text { químicos, } \\
\text { refinados y } \\
\text { derivados }\end{array}$ & $\begin{array}{l}\text { Plantaciones } \\
\text { y aceite de } \\
\text { palma crudo }\end{array}$ & $\begin{array}{c}\text { Oleo } \\
\text { químicos, } \\
\text { refinados y } \\
\text { derivados }\end{array}$ \\
\hline IOI & $10,737,284.22$ & $2,779,215.78$ & $10,044,184.64$ & $2,599,815.36$ & $9,231,530.34$ & $2,389,469.66$ & $9,325,505.91$ & $2,413,794.09$ & $11,222,493.64$ & $2,904,806.36$ \\
\hline $\begin{array}{l}\text { INDOFOOD } \\
\text { FELDA }\end{array}$ & $326,322.78$ & $603,261.68$ & $360,455.48$ & $686,935.41$ & $379,322.65$ & $589,158.43$ & $347,521.79$ & $669,643.87$ & $709,629.20$ & $721,934.43$ \\
\hline $\begin{array}{l}\text { PT ASGRA } \\
\text { GOLDEN }\end{array}$ & $886,631.34$ & - & $948,561.84$ & $192,846.33$ & $641,853.28$ & $272,291.84$ & $695,683.96$ & $292,812.22$ & $916,882.80$ & $294,515.36$ \\
\hline AGRI & $5,267,636.00$ & $120,128.00$ & $6,574,055.00$ & - & $5,686,540.00$ & - & $6,331,532.00$ & - & $7,507,599.00$ & 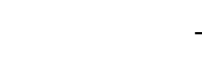 \\
\hline KLK & $951,539.38$ & $1,130,785.68$ & $1,225,413.51$ & $1,356,523.22$ & $1,679,709.57$ & $1,502,661.17$ & $2,009,161.22$ & $1,863,203.36$ & $2,534,699.13$ & $2,568,567.56$ \\
\hline WILMAR & $1,373,592.31$ & $19,456,572.00$ & $1,342,430.57$ & $19,785,488.00$ & $1,208,195.22$ & $15,607,278.00$ & $1,289,986.20$ & $16,768,176.00$ & $1,366,155.81$ & $17,970,078.00$ \\
\hline
\end{tabular}

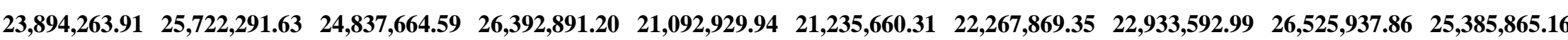

Nota: En miles de USD\$.

Fuente: IOI Group (2019), Astra Agro Lestari (2019), Golden Agri-Resources Limited (2019), Indofood TBK (2019), Felda Globe (2019), Kuala Lumpur Kepong Berhad (2019),Wilmar International (2019).

Elaboración propia. 


\section{Anexo 2 Crecimiento anual ponderado de segmentos de IOI}

\begin{tabular}{cccr} 
& $\begin{array}{c}\text { Plantaciones y } \\
\text { aceite de palma } \\
\text { crudo }\end{array}$ & $\begin{array}{c}\text { Oleo químicos, } \\
\text { refinados y } \\
\text { derivados }\end{array}$ & TOTAL \\
\cline { 2 - 4 } $\mathbf{2 0 1 3}$ & $23,894,263.91$ & $25,722,291.63$ & $\mathbf{4 9 , 6 1 6 , 5 5 5 . 5 4}$ \\
$\mathbf{2 0 1 4}$ & $24,837,664.59$ & $26,392,891.20$ & $\mathbf{5 1 , 2 3 0 , 5 5 5 . 7 9}$ \\
$\mathbf{2 0 1 5}$ & $21,092,929.94$ & $21,235,660.31$ & $\mathbf{4 2 , 3 2 8 , 5 9 0 . 2 6}$ \\
$\mathbf{2 0 1 6}$ & $22,267,869.35$ & $22,933,592.99$ & $\mathbf{4 5 , 2 0 1 , 4 6 2 . 3 4}$ \\
$\mathbf{2 0 1 7}$ & $26,525,937.86$ & $25,385,865.16$ & $\mathbf{5 1 , 9 1 1 , 8 0 3 . 0 1}$ \\
TOTAL & $\mathbf{1 1 8 , 6 1 8 , 6 6 5 . 6 6}$ & $\mathbf{1 2 1 , 6 7 0 , 3 0 1 . 2 8}$ & $\mathbf{2 4 0 , 2 8 8 , 9 6 6 . 9 4}$ \\
\cline { 2 - 4 } & $\mathbf{4 9 . 3 7 \%}$ & $\mathbf{5 0 . 6 3 \%}$ & \\
CARG 2013-2017 & $\mathbf{2 . 6 5 \%}$ & $\mathbf{- 0 . 3 3 \%}$ & \\
& & &
\end{tabular}

Nota: En miles de USD

Fuente: IOI Group (2019), Astra Agro Lestari (2019), Golden Agri-Resources Limited (2019), Indofood TBK (2019), Felda Globe (2019), Kuala Lumpur Kepong Berhad (2019),Wilmar International (2019).

Elaboración propia. 


\section{Anexo 3 Participación relativa de IOI en sus segmentos}

\begin{tabular}{ccccc} 
Segmento & Ventas IOI & $\begin{array}{c}\text { Principal } \\
\text { Competidor }\end{array}$ & $\begin{array}{c}\text { Crecimiento } \\
\text { Mercado }\end{array}$ & $\begin{array}{c}\text { Participación } \\
\text { Relativa }\end{array}$ \\
\hline $\begin{array}{c}\text { Plantaciones y } \\
\text { aceite de palma } \\
\text { crudo }\end{array}$ & $11,222,493.64$ & $11,222,493.64$ & $2.65 \%$ & 1.00 \\
$\begin{array}{c}\text { Oleo químicos, } \\
\text { refinados y } \\
\text { derivados }\end{array}$ & $2,904,806.36$ & $17,970,078.00$ & $-0.33 \%$ & 0.16
\end{tabular}

Nota: En miles de USD

Fuente: IOI Group (2019), Astra Agro Lestari (2019), Golden Agri-Resources Limited (2019), Indofood TBK (2019), Felda Globe (2019), Kuala Lumpur Kepong Berhad (2019), Wilmar International (2019).

Elaboración propia. 
Anexo 4 Valorización de IOI

\begin{tabular}{|c|c|c|c|c|c|c|c|c|c|}
\hline MYR m & 2017 & 2018 & 2019 & 2020 & 2021 & 2022 & 2023 & 2024 & 2025 \\
\hline Revenue & $14,127.30$ & $14,284.26$ & $14,726.56$ & $15,624.84$ & $16,782.59$ & $17,521.01$ & $18,438.87$ & $19,504.85$ & $20,616.94$ \\
\hline EBIT & $1,261.40$ & $1,327.53$ & $1,376.38$ & $1,475.59$ & $1,603.45$ & $1,685.00$ & $1,786.36$ & $1,904.09$ & $2,026.91$ \\
\hline NOPAT & 958.66 & $1,008.93$ & $1,046.05$ & $1,121.45$ & $1,218.62$ & $1,280.60$ & $1,357.64$ & $1,447.11$ & $1,540.45$ \\
\hline AFN & $10,086.90$ & $10,339.07$ & $10,597.55$ & $10,862.49$ & $11,405.61$ & $11,975.89$ & $12,574.69$ & $13,832.16$ & $15,215.37$ \\
\hline Depreciation PPE & 479.70 & 485.03 & 500.05 & 530.55 & 569.86 & 594.94 & 626.10 & 662.30 & 700.06 \\
\hline CAPEX & 87.60 & 252.17 & 258.48 & 264.94 & 543.12 & 570.28 & 598.79 & $1,257.47$ & $1,383.22$ \\
\hline INV WC (Variación) & 368.20 & 317.56 & 12.27 & 172.46 & 246.06 & 952.33 & $1,271.42$ & 234.32 & 245.49 \\
\hline FCLu / F.ECO & 982.56 & $1,559.35$ & $1,299.89$ & $1,214.59$ & 999.30 & $2,257.58$ & 113.52 & 617.62 & 611.80 \\
\hline Prestamos & 561.80 & 891.59 & 743.24 & 694.47 & 571.37 & $1,290.82$ & 64.91 & 353.13 & 349.81 \\
\hline Amortización & - & - & - & - & & - & - & - & - \\
\hline Interéses & 33.71 & 53.50 & 44.59 & 41.67 & 34.28 & 77.45 & 3.89 & 21.19 & 20.99 \\
\hline Esc.Fiscal & 8.09 & 12.84 & 10.70 & 10.00 & 8.23 & 18.59 & 0.93 & 5.09 & 5.04 \\
\hline FCLi / F.FIN & 956.95 & $1,518.69$ & $1,266.00$ & $1,182.92$ & 973.24 & $2,198.72$ & 110.56 & 601.51 & $\mathbf{5 9 5 . 8 5}$ \\
\hline
\end{tabular}

Continúa 


\begin{tabular}{lrrrrrrrrr} 
Cap Ope & $\mathbf{6 , 2 7 6 . 1 0}$ & $\mathbf{6 , 1 5 6 . 0 5}$ & $\mathbf{6 , 2 2 4 . 4 5}$ & $\mathbf{6 , 2 9 3 . 6 0}$ & $\mathbf{6 , 3 6 3 . 5 3}$ & $\mathbf{6 , 4 3 4 . 2 3}$ & $\mathbf{6 , 5 0 5 . 7 2}$ & $\mathbf{6 , 5 7 8 . 0 1}$ & $\mathbf{6 , 6 5 1 . 0 9}$ \\
Cap Inv & $\mathbf{1 6 , 3 6 3 . 0 0}$ & $\mathbf{1 6 , 4 9 5 . 1 2}$ & $\mathbf{1 6 , 8 2 1 . 9 9}$ & $\mathbf{1 7 , 1 5 6 . 0 9}$ & $\mathbf{1 7 , 7 6 9 . 1 4}$ & $\mathbf{1 8 , 4 1 0 . 1 3}$ & $\mathbf{1 9 , 0 8 0 . 4 1}$ & $\mathbf{2 0 , 4 1 0 . 1 6}$ & $\mathbf{2 1 , 8 6 6 . 4 7}$ \\
ROIC & $\mathbf{6 . 0 8 \%}$ & $\mathbf{6 . 1 7 \%}$ & $\mathbf{6 . 3 4 \%}$ & $\mathbf{6 . 6 7 \%}$ & $\mathbf{7 . 1 0 \%}$ & $\mathbf{7 . 2 1} \%$ & $\mathbf{7 . 3 7 \%}$ & $\mathbf{7 . 5 8 \%}$ & $\mathbf{7 . 5 5 \%}$ \\
ROA & $\mathbf{4 . 2 5 \%}$ & $4.32 \%$ & $4.39 \%$ & $4.84 \%$ & $\mathbf{5 . 0 2} \%$ & $\mathbf{5 . 3 5 \%}$ & $\mathbf{5 . 4 4 \%}$ & $\mathbf{5 . 3 9 \%}$ & $\mathbf{5 . 3 3 \%}$ \\
ROE & $\mathbf{9 . 9 3 \%}$ & $10.14 \%$ & $10.24 \%$ & $\mathbf{1 2 . 0 1 \%}$ & $\mathbf{1 2 . 3 0 \%}$ & $\mathbf{1 2 . 4 0 \%}$ & $\mathbf{1 4 . 3 7 \%}$ & $\mathbf{1 4 . 5 7 \%}$ & $\mathbf{1 4 . 7 5 \%}$ \\
\hline EVA & & $\mathbf{5 8 . 4 5 2 1 2 8}$ & $\mathbf{6 0 . 6 0 2 8 5 6}$ & $\mathbf{6 4 . 9 7 0 9 3 0 8}$ & $\mathbf{7 0 . 6 0 0 6 9 0 4}$ & $\mathbf{7 4 . 1 9 1 3 5 3 9}$ & $\mathbf{7 8 . 6 5 4 6 3 4 4}$ & $\mathbf{8 3 . 8 3 8 1 4 1 2}$ & $\mathbf{8 9 . 2 4 5 9 0 5 9}$ \\
\hline
\end{tabular}

Fuente: Bloomberg (2019), Damodaran (2019), SyP 500 (2019) Elaboración Propia 


\section{Anexo 5 Estado de Situación Financiera de IOI}

\begin{tabular}{|c|c|c|c|c|c|c|c|c|c|c|c|c|c|c|}
\hline & 2012 & 2013 & 2014 & 2015 & 2016 & 2017 & 2018 & 2019 & 2020 & 2021 & 2022 & 2023 & 2024 & 2025 \\
\hline \multicolumn{15}{|l|}{ ACTIVOS } \\
\hline $\begin{array}{l}\text { Property, } \\
\text { Plant and }\end{array}$ & & & & & & & & & & & & & & \\
\hline $\begin{array}{l}\text { Equipment } \\
\text { Prepaid Lease }\end{array}$ & $7,572.6$ & $7,772.5$ & $6,410.0$ & $6,649.8$ & $9,999.3$ & $10,086.9$ & $10,339.1$ & $10,597.6$ & $10,862.5$ & $11,405.6$ & $11,975.9$ & $12,574.7$ & $13,832.2$ & $15,215.4$ \\
\hline Payments & 29.6 & 129.2 & 30.1 & 32.5 & 21.1 & - & - & - & - & & - & & - & \\
\hline $\begin{array}{l}\text { Investment } \\
\text { Jointly }\end{array}$ & $2,143.9$ & $2,820.1$ & 895.2 & 946.8 & 944.4 & $1,121.1$ & $1,133.6$ & $1,168.7$ & $1,240.0$ & $1,331.8$ & $1,390.4$ & $1,463.3$ & 1,5479 & $1,636.1$ \\
\hline $\begin{array}{l}\text { Controlled } \\
\text { Entities }\end{array}$ & $3,483.1$ & $3,686.1$ & 33.0 & 35.2 & 31.7 & - & - & - & - & - & - & - & - & \\
\hline $\begin{array}{l}\text { Other Assets } \\
\text { Total Non- } \\
\text { Current }\end{array}$ & 650.1 & 647.1 & 577.3 & 643.5 & 708.0 & 781.7 & 790.4 & 814.9 & 864.6 & 928.6 & 969.5 & $1,020.3$ & $1,079.3$ & $1,140.8$ \\
\hline $\begin{array}{l}\text { Assets } \\
\text { Current }\end{array}$ & $13,879.3$ & $15,055.0$ & $7,945.6$ & $8,307.8$ & $11,704.5$ & $11,989.7$ & $12,263.0$ & $12,581.1$ & $12,967.0$ & $13,666.1$ & 14,3358 & $15,058.2$ & $16,459.3$ & $17,992.3$ \\
\hline Assets & $9,185.6$ & $8,846.7$ & $7,386.0$ & $5,126.1$ & $5,851.6$ & $6,035.0$ & $6,102.1$ & $6,291.0$ & $5,567.6$ & $5,980.1$ & $5,132.7$ & $5,401.6$ & $5,713.8$ & $6,039.6$ \\
\hline Total Assets & $23,064.9$ & $23,901.7$ & $15,331.6$ & $13,433.9$ & $17,556.1$ & $18,024.7$ & $18,365.1$ & $18,872.1$ & $18,534.6$ & $19,646.8$ & $19,468.5$ & $20,459.8$ & $22,173.1$ & $24,031.9$ \\
\hline
\end{tabular}


(continuación)

PASIVOS Y

PATRIMONIO

PATRIMONIO

\begin{tabular}{|c|c|c|c|c|c|c|c|c|c|c|c|c|c|c|}
\hline Share Capital & 642.7 & 643.4 & 645.0 & 645.9 & 646.2 & 783.8 & 815.5 & 855.1 & 904.8 & 967.9 & $1,049.3$ & $1,112.3$ & $1,183.6$ & $1,263.1$ \\
\hline \multirow{2}{*}{$\begin{array}{l}\text { Reserves } \\
\text { Total Equity and } \\
\text { reserves }\end{array}$} & $11,985.2$ & $13,028.6$ & $5,391.8$ & $4,413.2$ & $6,491.9$ & $6,673.6$ & $6,747.8$ & $6,956.7$ & $6,273.9$ & $6,738.7$ & $7,035.2$ & $6,293.2$ & $6,657.0$ & $7,036.6$ \\
\hline & $12,627.9$ & $13,672.0$ & $6,036.8$ & $5,059.1$ & $7,138.1$ & $7,457.4$ & $7,563.3$ & $7,811.8$ & $7,178.6$ & $7,706.6$ & $8,084.5$ & $7,405.6$ & $7,840.6$ & $8,299.7$ \\
\hline Minority Interests & 288.0 & 280.0 & 196.3 & 189.3 & 278.9 & 261.3 & 264.2 & 272.4 & 289.0 & 310.4 & 324.1 & 341.1 & 360.8 & 381.3 \\
\hline Total Equity & $12,915.9$ & $13,952.0$ & $6,233.1$ & $5,248.4$ & $7,417.0$ & $7,718.7$ & $7,827.5$ & $8,084.2$ & $7,467.6$ & $8,017.0$ & $8,408.6$ & $7,746.6$ & $8,201.4$ & $8,681.0$ \\
\hline \multicolumn{15}{|l|}{ PASIVOS } \\
\hline $\begin{array}{l}\text { Non-Current } \\
\text { Liabilities }\end{array}$ & $7,946.5$ & $8,280.9$ & $5,601.7$ & $6,320.2$ & $6,314.7$ & $6,666.4$ & $6,740.5$ & $6,949.2$ & $7,373.1$ & $7,919.4$ & $8,267.8$ & $8,701.0$ & $9,203.9$ & $9,728.7$ \\
\hline Current Liabilities & $2,202.5$ & $1,668.8$ & $3,496.8$ & $1,865.3$ & $3,824.4$ & $3,639.6$ & $4,024.2$ & $4,225.4$ & $3,329.5$ & $3,496.0$ & $3,600.9$ & $2,598.4$ & $2,676.3$ & $2,756.6$ \\
\hline Total Liabilities & $10,149.0$ & $9,949.7$ & $9,098.5$ & $8,185.5$ & $10,139.1$ & $10,306.0$ & $10,764.7$ & $11,174.6$ & $10,702.6$ & $11,415.4$ & $11,868.7$ & $11,299.3$ & $11,880.3$ & $12,485.3$ \\
\hline $\begin{array}{l}\text { Total Equity and } \\
\text { Liabilities }\end{array}$ & $23,064.9$ & $23,901.7$ & $15,331.6$ & $13,433.9$ & $17,556.1$ & $18,024.7$ & $18,592.2$ & $19,258.8$ & $18,170.2$ & $19,432.4$ & $20,277.3$ & $19,045.9$ & $20,081.6$ & $21,166.3$ \\
\hline
\end{tabular}

Elaboración propia 
